\title{
Atmospheric Discharge Caused by Methane Emission in Permafrost Degradation Area Caused Wildfire
}

Wei Shan ( $\nabla$ shanwei456@163.com )

Northeast Forestry University

Zhichao Xu

Northeast Forestry University

Ying Guo

Northeast Forestry University

Chengcheng Zhang

Northeast Forestry University

Research Article

Keywords: permafrost, methane hydrate, geological methane emission, electrostatic field, wildfire

Posted Date: May 28th, 2021

DOl: https://doi.org/10.21203/rs.3.rs-540805/v1

License: (c) (i) This work is licensed under a Creative Commons Attribution 4.0 International License. Read Full License 


\title{
Atmospheric discharge caused by methane emission in permafrost degradation area caused wildfire
}

\author{
Wei Shan ${ }^{1,2 . *}$, Zhichao $\mathrm{Xu}^{1}$, Ying Guo ${ }^{1,2}$, Chengcheng Zhang ${ }^{1,2}$
}

1. Institute of Cold Regions Science and Engineering, Northeast Forestry University, Harbin 150040, China;

2. Field scientific observation and research station of the Ministry of Education - Geological environment system of permafrost area in Northeast China(FSSE-PFNEC), Harbin 150040, China.

* Corresponding Author, E-mail: Shanwei456@163.com

Abstract

With the development of global warming, the carbon pool in the degraded permafrost zone around the Arctic will gradually be disturbed and enter the atmosphere in the form of methane gas. The frequency and intensity of forest fires will gradually increase, and the release of geological methane will become important factors affecting wildfires in permafrost regions. The northwestern section of China's Xiao Xing'an Mountains, which is located in the degradation zone of the southern edge of the permafrost region of Eurasia, was selected as the research area. Monitoring equipment such as atmospheric electric field, air temperature, methane concentration, soil temperature and pore water pressure were deployed to monitor relevant data changes for a long time. Through indoor soil ventilation tests, it was verified that the friction between gas and soil particles caused the difference in soil electric potential, and the analysis revealed the mechanism of seasonal wildfires in the study area. The results show that the gradual decomposition of metastable methane hydrate and stable methane hydrate stored in the permafrost in the northern part of the Xiao Xing'an Mountains in Northeast China is the main source of high-concentration methane gas entering the atmosphere from the surface. In spring, as the frozen layer on the surface of the study area thaws and the snow gradually melts, the high-concentration, high-pressure methane gas accumulated under the frozen layer will be quickly released into the atmosphere. The study area has the annual maximum value of methane concentration on the surface every spring (March to May), and the rapid rise of gas molecules during the decomposition of underground methane hydrate will cause friction with soil particles, causing methane molecules to be positively charged. Under the action of soil pore pressure and the negative charge at the bottom of the near-surface cloud layer, positively charged methane gas enters the atmosphere. The positively charged methane gas in the air contacts the negative charge in the near-surface cloud layer to form a discharge channel to enhance the discharge phenomenon. With the gradual accumulation of positive charges in the air, the positively charged methane in the air near the ground and the water molecules in the air form positively charged aerosols, and contact with the negative charges near the ground will also form a discharge channel to produce a discharge phenomenon, which will lead to high concentrations of methane gas near the surface were ignited. In addition, the mixed gas with higher pressure and concentration will reduce the thermal spontaneous combustion temperature of methane gas, and when methane aerosol is formed, it will further increase the impact on the air temperature, thereby increasing the risk of wildfires. The electric potential difference between the ground and the near-surface and the flammability of methane aerosols caused by the methane gas emission process in the permafrost degraded area will become an important factor in inducing wildfires.

Keywords: permafrost; methane hydrate; geological methane emission; electrostatic field; wildfire Intruction

Earth's cryosphere constitutes a huge climate-sensitive carbon reservoir, not only in the form of permafrost soil carbon, but also in the form of methane reservoirs under the permafrost and ice caps ${ }^{1-3}$. There is not only a deep methane hydrate stable zone in the permafrost region, and the permafrost layer cannot be completely permeable to gas, and a considerable part of the gas accumulates in the form of metastable methane hydrate ${ }^{4,5}$. The IPCC special report pointed out that due to the impact of greenhouse gas emissions, global warming has caused the earth's average temperature to be $1{ }^{\circ} \mathrm{C}$ higher than the level before industrialization ${ }^{6}$, and the temperature increase in high latitudes and high altitude areas is faster than other regions, which are also the main distribution areas of permafrost. Climate change threatens this huge carbon pool. Since 2007, the global atmospheric methane concentration continued to rise after it remained stable between 1990 and $2006^{7,8}$. In many areas, the area of the Gas Hydrate Stability Zone (GHSZ) is gradually shrinking, and it is gradually entering the atmosphere in the form of methane gas ${ }^{9-11}$.

Up to $80 \%$ of the boreal forest area is located in the polar permafrost. In the permafrost regions of Siberia, forest fires burn 50,000-200,000 hectares of boreal forest every year. In the past two decades, fires have destroyed at least $1 \%$ of the forest area each year ${ }^{12-15}$, and the frequency of fires has increased ${ }^{16}$, which will lead to a significant increase in the disturbance of the Siberian ecosystem in the future. With the impact of climate change and large-scale wildfires, it has caused abnormal processes in permafrost temperature balance, annual thermal conditions, and seasonal dynamics of the seasonal activity layer ${ }^{17-20}$. These wildfires emit a lot of carbon and change the ecology of the region. In 2020 alone, wildfires in the Arctic Circle will emit 244MtCO2, which is almost half of Canada's annual emissions ${ }^{23,24}$. Lightning is closely related to the microscopic physics and dynamics of thunderstorms ${ }^{25-28}$. Studies have found that lightning is the main cause of wildfires in permafrost regions near the $\operatorname{Arctic}^{21-23}$. Studies have shown that 
by the end of this century, under the background that the global average temperature will rise by $3.7^{\circ} \mathrm{C}$, lightning in permafrost area may increase $74-150 \%^{23,24}$, this is three times higher than most previous estimates of the global lightning response to global warming ${ }^{21,22}$. Permafrost will further thaw after forest fires, and the respiration rate of microorganisms after the fire is three times that before the fire, which greatly increases the diffusion of $\mathrm{CO}_{2}, \mathrm{CH}_{4}$ and $\mathrm{N}_{2} \mathrm{O}$ in the atmosphere ${ }^{29}$. At the same time, the fire affects the water and heat conditions of the permafrost area. After the fire, the surface albedo is reduced, resulting in a change in the surface heat condition, the thickness of the active layer deepens, the loss of organic carbon and nutrients is accelerated, and eventually a feedback mechanism of lightning-wildfirevegetation to permafrost is formed ${ }^{22}$. However, we find that methane released gradually in permafrost regions may further promote this feedback mechanism and increase the risk of wildfire in permafrost degraded regions ${ }^{30}$.

In order to further study the influence mechanism of methane gas release in permafrost regions on the occurrence of wildfires, we selected the northwestern section of China's Xiao Xing'an Mountains, located in the degradation zone of the southern margin of the permafrost regions of Eurasia, as the research area, set up multiple research monitoring areas, and set up atmospheric electric fields, air temperature, methane concentration, soil temperature and pore water pressure and other monitoring equipment, long-term monitoring of relevant data changes. Through indoor soil ventilation tests, it was verified that the friction between gas and soil particles caused the difference in electric potential, and the analysis revealed the mechanism of seasonal wildfires in the study area.

\section{Study area description}

The permafrost regions in Southeast Siberia and Northeast China which are located in the southern margin of the Eurasian permafrost region have poor thermal stability and strong ecological sensitivity in cold regions. Under the combined influence of regional geological conditions, climate change and human activities, the permafrost is degrading, with a transition of continuous permafrost to discontinuous permafrost to sporadic permafrost and even isolated patches from north to south ${ }^{31}$ (Fig. 1). The area of permafrost in Northeast China is about $354,700 \mathrm{~km}^{2}$. The temperature of permafrost is high, the thickness is thin, and the thermal state is unstable. It is susceptible to interference from the external environment, climate and human factors $^{32-36}$. The mean annual air temperature (MAAT) growth in Northeast China is higher than the global MAAT growth, making the region more affected by temperature changes ${ }^{37-39}$. Since 1980, MAAT fluctuations in Northeastern China have increased, and higher latitudes have experienced more extreme warming ${ }^{40}$, especially in the northern part of the Da Xiao Xing'an Mountains ${ }^{41}$. In the past 50 years, the temperature in northeastern China has generally increased by $0.9 \sim 2.2^{\circ} \mathrm{C}$, which has caused the southern edge of the permafrost region of Eurasia to shift to the north. The area of the permafrost region has decreased by $35 \% \sim 37 \%$ compared with the $1970 \mathrm{~s}$. If the temperature rises by $1 \sim 1.5^{\circ} \mathrm{C}$ in the next 40-50 years, the southern edge of the permafrost region of Eurasia will move further north, and the area of permafrost may decrease by another $35 \%^{36}$.

In this paper, the permafrost swamp area of K153-K183 section of Bei'an-Heihe Expressway in Xiao Xing'an Mountains on the edge of Sunwu-Jiayin basin in China (integrated with the Breya-Gaya Basin in Russia to the north) is selected as the study area, and its geographical location is between $127^{\circ} 17^{\prime} 31^{\prime \prime} \mathrm{E}$, $127^{\circ} 21^{\prime} 24^{\prime \prime} \mathrm{E}$ and $49^{\circ} 30^{\prime} 57^{\prime \prime} \mathrm{N}, 49^{\circ} 41^{\prime} 50^{\prime \prime} \mathrm{N}$, as shown in Figure 1 . This area belongs to low mountain and hilly landform area, with an altitude between 110 and $755 \mathrm{~m}$. There are cold temperate coniferous and broad-leaved mixed forests at high altitudes, moss grass grows on the lower surface, and thick peat soils are distributed on the soil surface. Swamp wetlands and permafrost are distributed mostly in relatively low-lying areas and floodplains, with thicknesses of approximately 5-10m, average ground temperatures of $-0.5^{\circ} \mathrm{C} \sim-5^{\circ} \mathrm{C}$, and melting permafrost areas of more than $80 \%$. Select the permafrost swamp zone on the left side of the K161+300-K161+900 and K177+400-K177+800 sections of the Bei'an-Heihe Expressway, and set up the study monitoring area R-1 $\left(49^{\circ} 30^{\prime} 52^{\prime \prime} \mathrm{N}, 127^{\circ} 18^{\prime} 21^{\prime \prime} \mathrm{E}\right.$, altitude $\left.278 \mathrm{~m}\right)$ and R-2 $\left(49^{\circ} 39^{\prime} 28^{\prime \prime} \mathrm{N}, 127^{\circ} 21^{\prime} 5^{\prime \prime} \mathrm{E}\right.$, altitude $\left.229 \mathrm{~m}\right)$. Deploy monitoring equipment such as atmospheric electric field, methane concentration, soil pore water pressure, air temperature and ground temperature in the study area R-1. Since June 2015, the changes in related parameters of R-1 have been monitored. In January 2018, monitoring equipment for methane concentration, air temperature, and ground temperature was added to the study area R-2 to monitor the methane concentration on the surface in real time. 


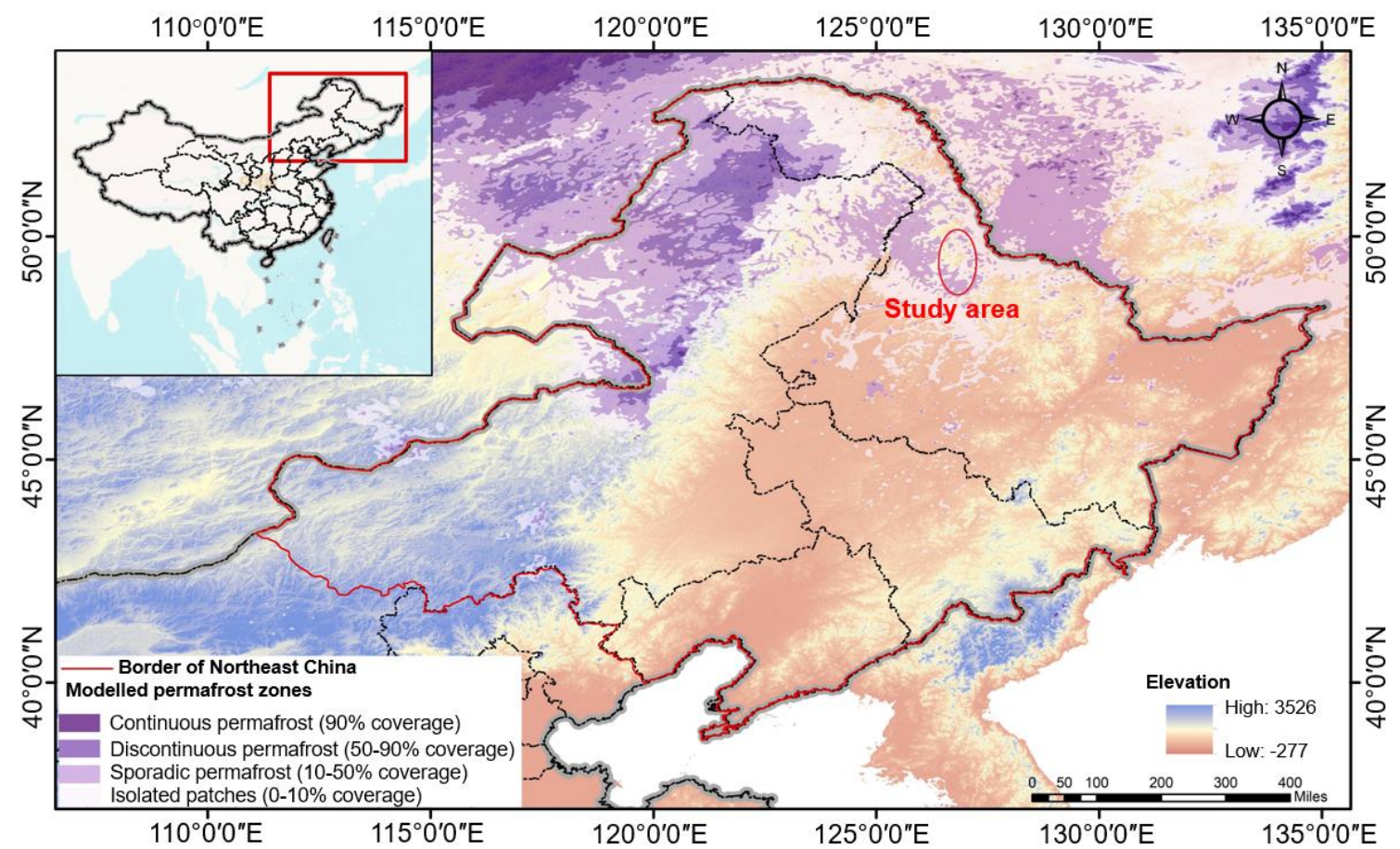

Figure 1. Distribution map of permafrost in Northeast China and location of the study area, according to the degree of permafrost coverage, divided into continuous permafrost (>90\%), discontinuous permafrost (50-90\%), sporadic permafrost (10-50\%), isolated patches (0-10\%); data from Jaroslav O. et al. (2019)

\section{Methane emissions from permafrost regions in Northeast China}

Due to the comprehensive influence of climate, topography, vegetation and other factors, the distribution of permafrost in the high latitudes of the Northeast China has the characteristics of being located in low-lying and shady slopes, and the degradation has the law from high to low, from sunny slopes to shady slopes. These special phenomena constitute the distribution and degradation characteristics of frozen soil in "Xing'an-Baikal"42. Among them, the thickness of the permafrost layer of the swamp wetland in the study area has gradually decreased, and the degradation rate has accelerated significantly after 2004; the organic matter and methane hydrate (metastable methane hydrate and stable methane hydrate) stored in the frozen soil layer of the swamp wetland is gradually entering the atmosphere in the form of methane gas. The methane gas emission changes seasonally. The annual methane gas release is mainly divided into three stages, including the high-concentration short-term emission stage (March to May), the higher-concentration long-term stable emission stage (June to August) and the higher-concentration short-term emission stage (September-November), as shown in Figure 2. In addition, the pressure gradient in the migration process of methane gas is an important driving force. The magnitude of the pressure gradient directly determines the speed of methane gas entering the atmosphere through the soil layer. When methane gas enters the atmosphere, the change law of pore water pressure and atmospheric pressure determines the speed of methane gas entering the atmosphere, that is, when the atmospheric pressure is small and the pore water pressure is large, the methane gas may enter the atmosphere more easily. It can be seen from the isoline map of $0-12 \mathrm{~m}$ ground temperature change that there are several positive temperature regions at $0-6 \mathrm{~m}$ ground temperature from February to march in 2019, which may be related to the release of methane gas, as shown in Figure 2c. From March to May of each year (high concentration short-term emission stage), with the snow melting, the air humidity reaches the annual low value, and the annual maximum of surface methane concentration appears. The high concentration of methane gas entering the surface at this stage may be an important factor leading to the difference in the frequency, peaks in spring and autumn and monthly maximum in spring of seasonal wildfires in the permafrost zones of Northeast China and Southeast Siberia ${ }^{27-30}$.

We further use sentinel-2 L1C satellite image to obtain the wildfire burned area on March 24, 2021 in the study area and compare it with the permafrost distribution area (Figure 3). It can be seen that the distribution of wildfires in the spring of 2021 is consistent with that of permafrost, which further proves the correlation between the distribution of wildfires and permafrost in the study area. 

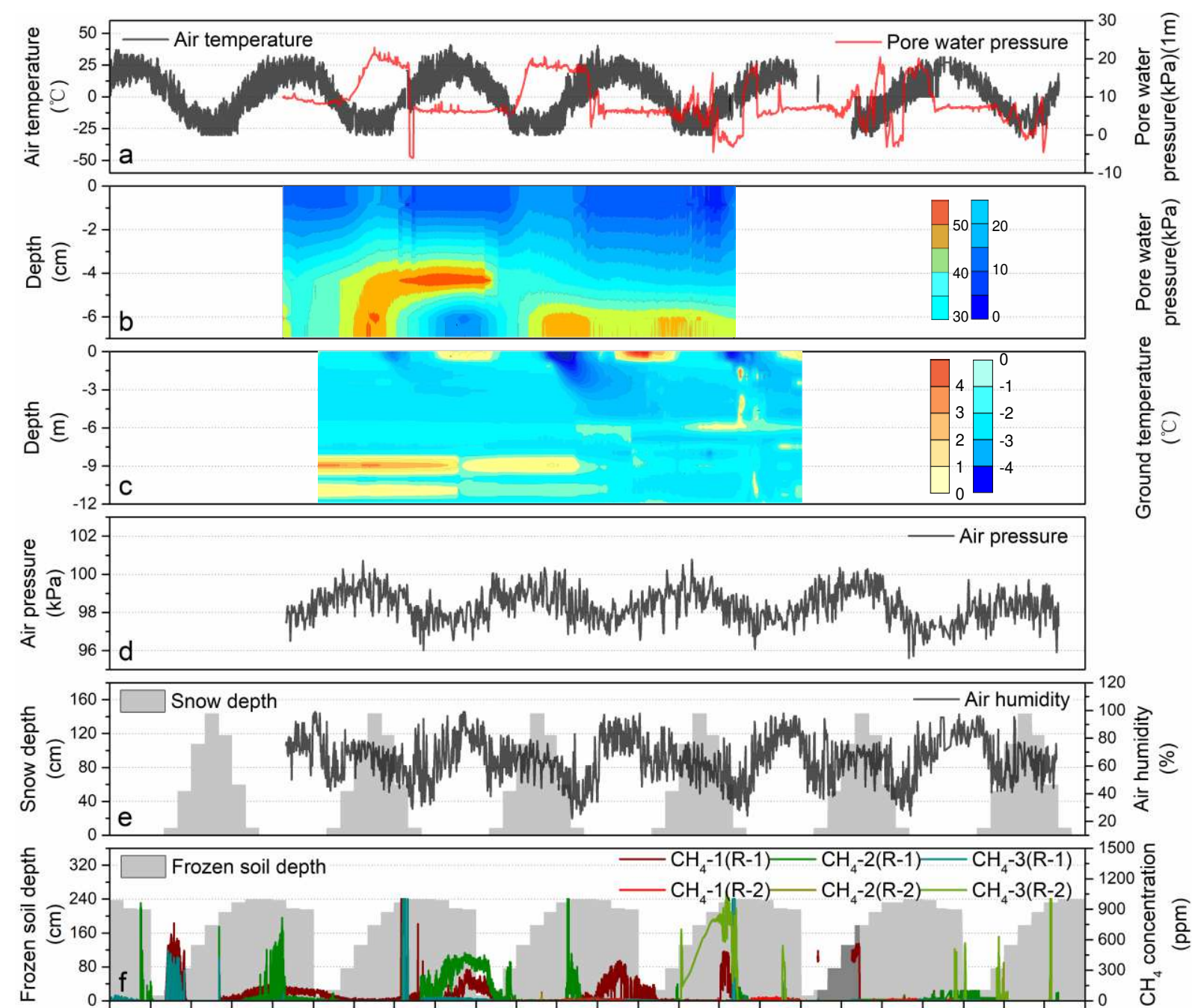

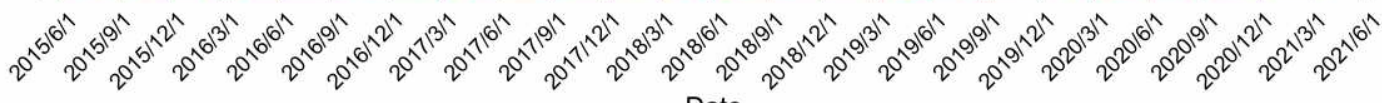

Date

Figure 2. Change of monitoring factors in study area R-1 and R-2. a Pore water pressure at depth of $1 \mathrm{~m}$ underground and air temperature in study area R-1, b Isoline map of soil pore water pressure at depth of $0-7 \mathrm{~m}$ in study area R-1, c Isoline map of ground temperature at 0-12m at depth of R-1 in study area R-1, $\mathbf{d}$ Atmospheric pressure in the study area $\mathrm{R}-1$, e Atmospheric relative humidity and average snow cover thickness in the study area R-1, $\mathbf{f}$ Surface methane concentration and the monthly maximum active layer thickness (frozen soil depth, distance from the surface to the upper limit of frozen soil) in study area R-1 and R-2.

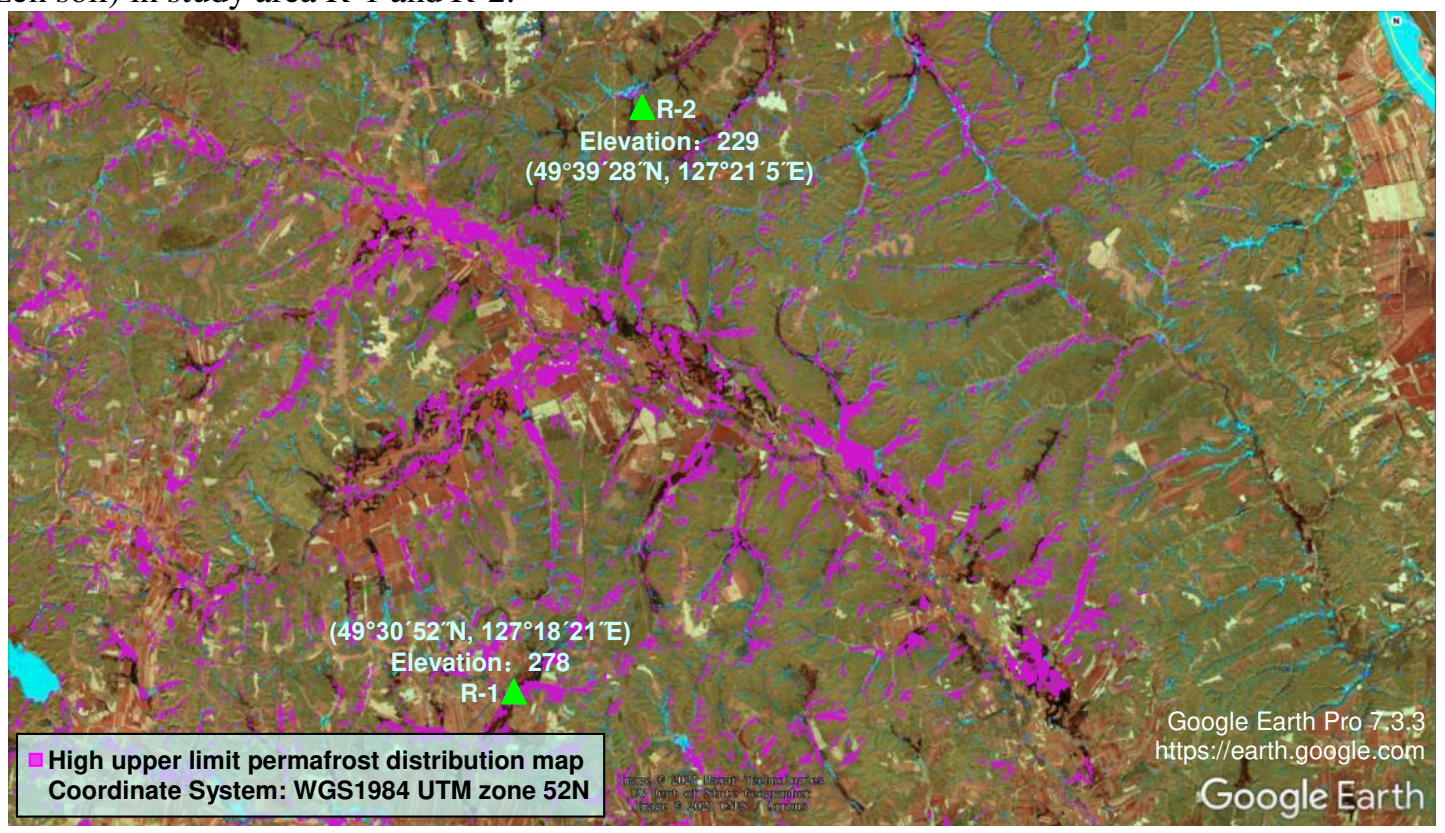

Figure 3. Location coordinates of R-1 and R-2 in the study area, distribution of frozen soil nearby and burned area (March 24, 2021). The pink area is the distribution area of permafrost, and the data comes from Wang C. et al. (2015) ${ }^{33}$. 
The black area is the burned area, and the red area is the fire spot.

\section{Lightning formation mechanism and near surface atmospheric electric field during geological methane emission in permafrost regions}

Lightning is an important cause of forest fires. Lightning strikes fire is related to geographical factors, and the location of lightning strikes is selective to the environment ${ }^{46}$. There are two types of lightning strike selection areas. One is due to the prominent geographical location of the area, that is, the selectivity of lightning strikes is mainly determined by the relative height factor; the other is that the soil resistivity of the underlying surface is relatively small in this area, that is, the lightning strike selectivity is mainly determined by the soil resistivity factors of the underlying surface, and swamp land are high lightning strike prone areas ${ }^{43-45}$.

Lightning is related to the breakdown of the air medium. Electric charges are separated in the thunderstorm cloud. The upper part of the thunderstorm cloud has a positive polarity and the lower part has a negative polarity ${ }^{44-46}$. The electric charge separation is mainly caused by the non-inductive electrification mechanism, that is, the collisions between ice crystals and sleet, between ice crystals, and between ice crystals and water droplets cause electrons to transfer from small particles to large particles. Under the action of vertical airflow and gravity, the positively charged particles move upward with the updraft, while the negatively charged particles move downward ${ }^{46,47}$. The negative charge at the bottom of the thunderstorm cloud induces a positive charge on the ground facing the thunderstorm cloud. When the electric field strength between the thunderstorm cloud and the ground reaches the breakdown field strength of humid air (about $3.3 \times 10^{5} \mathrm{~V} / \mathrm{m}$ ), the negative charge will leave the thunderstorm cloud and enter the air to form a stepped leader. The positive charge induced by the ground gradually accumulates and develops from the high objects above the ground to the air to form a positive charge flow column. Since the average electric field strength is inversely proportional to the distance, the electric field between the higher object on the ground and the stepped leader is the strongest. When the positive charge flow column is connected with one of the stepped leader, a discharge channel will be formed, and then an air discharge phenomenon will be generated, as shown in Figure 4a.

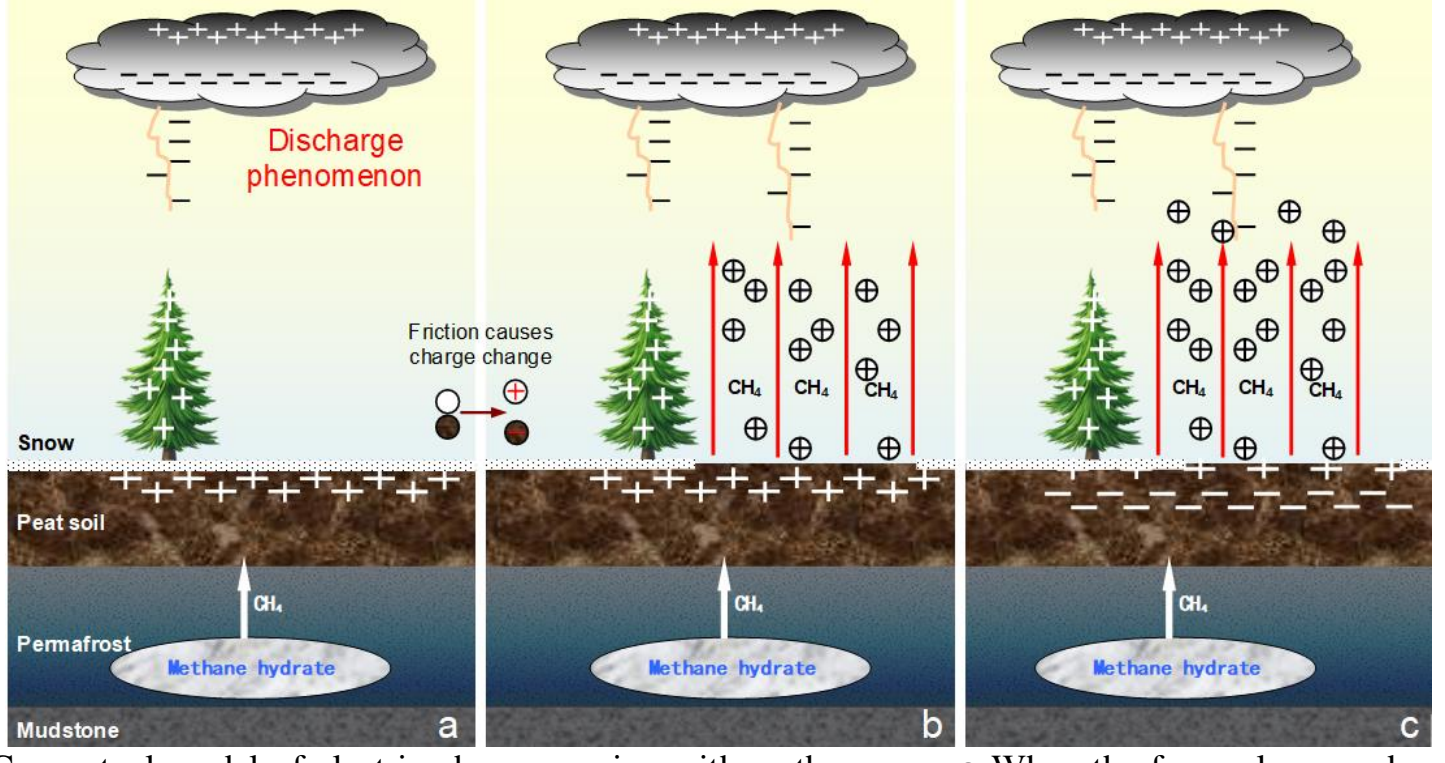

Figure 4. Conceptual model of electric charge moving with methane gas. a When the frozen layer and snow are not melted, positive charges on the ground gradually accumulate in high places (trees, etc.) to form a positive charge flow column, and contact with stepped leader in the air to cause discharge, b After the frozen layer and snow melt, the positive charges on the ground gradually accumulate in high places (trees, etc.) to form a positive charge flow column. The methane gas discharged outside strengthens the positive charge flow column and contacts the stepped leader, thereby enhancing the air discharge phenomenon. In this process, there are more positive charges on the ground, so the atmospheric electric field near the ground is mainly positive. c After the frozen layer and snow melt, the positive charges on the ground gradually accumulate in high places (trees, etc.) to form a positive charge flow column. The methane gas discharged outside strengthens the positive charge flow column and contacts the stepped leader, thereby enhancing the air discharge phenomenon. With the release of methane, the positive charges gradually enter the atmosphere, the positive charges on the ground gradually decrease, and the atmospheric electric field near the ground is mainly negative.

In addition, studies have shown that solids, liquids and even gases will be charged due to contact separation ${ }^{48,49}$. This is because gas is also composed of molecules and atoms. When air flows, molecules and atoms will "contact and separate" and become electrified ${ }^{49-54}$. In the spring, when the frozen layer on 
the surface of the permafrost gradually melts, the high-concentration, high-pressure methane gas accumulated under the frozen layer will be quickly released into the atmosphere. In the process of rapid movement of methane gas in the soil, it will rub against the soil particles, and the extranuclear electrons will get rid of the bondage, causing the positively charged methane gas to gradually enter the atmosphere. With the gradual release of methane gas, the positive charge released from the ground gradually increases and the positive charge flow column will gradually increase and strengthen, so as to contact the negative charge in the cloud layer near the ground to form a discharge channel and strengthen the discharge phenomenon. In this process, there are more positive charges on the ground, so the atmospheric electric field near the ground is mainly positive, as shown in Figure 4b. With the release of methane gas, the positive charge gradually enters the atmosphere, and the positive charge in the atmosphere gradually increases. The positively charged methane and the water molecules in the atmosphere near the ground form positively charged aerosols, and the positive charge on the ground gradually decreases. The atmospheric electric field near the ground is mainly negative, as shown in Figure 4c. Compared with air, methane gas has higher flammability and electrical conductivity, so the continuous near-ground atmospheric discharge phenomenon will ignite the methane gas.

In order to further verify the frictional charging process between gas and soil, we carried out indoor soil ventilation experiments, as shown in Figure 5a. The experimental results show that when gas is input to the soil of B test box, the A and B test boxes will form obvious voltage changes, and the overall trend is that as the gas input time increases, the voltage gradually increases and then stabilizes, as shown in Figure 5b. Therefore, the movement of the gas in the soil after the thawing of the frozen layer will cause the movement of the electric charge and have obvious electrification, and then enhance the change of the local electric field and the air discharge phenomenon in the region.
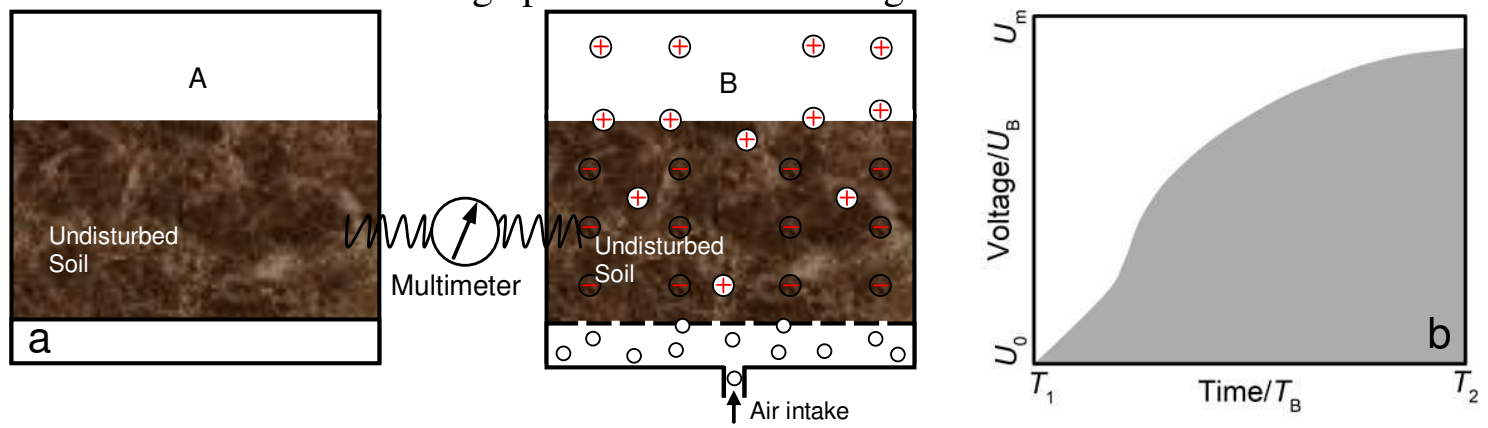

Figure 5. Schematic diagram of indoor soil ventilation test. a Indoor soil ventilation test, in which test box A is static, and gas input is carried out in the soil of test box B, b Curve of the voltage between the two test box as the gas enters.

\section{Analysis of the characteristics of burned sites, the changes of atmospheric electric field and related monitoring data in the study area}

Northeast China has a monsoon climate in the north temperate zone ${ }^{55}$. East or southeast wind prevails in the region in summer. Since the cyclones from Baikal Lake and Mongolia have more chances to form peak surface on ridges, the process of electric discharge and thunderstorms between the charged clouds and the ground often occurs, which not only causes thunderstorms, but also causes the ground temperature to increase and relative humidity to decrease, which promotes the drying of the ground cover, and is often accompanied by strong winds. Therefore, although the central area north of N51 lightning activity is not concentrated enough, but there are more thunderstorms, and thunderstorms, especially dry thunderstorms, are one of the main reasons for the formation of lightning fires ${ }^{56}$. There are three distribution zones of lightning fire in Northeast China ${ }^{57}$. The southwest is the Hulunbuir League, that is, the area south of $\mathrm{N} 51^{\circ}$, where lightning fire account for $18 \%$ of the total number of fires in this area. The east is swamp meadow, larix gmelini, birch forests and Mongolian oak forests in the Heihe area (the study area in this article). The northern is the hinterland of the mountains with an altitude of $800 \mathrm{~m}$ or the area within the larix gmelini forest and pinus sylvestris forest on the top of the mountain north of N51 ${ }^{\circ}$, these areas are the concentrated areas of lightning fire. From the spatial distribution of lightning fires for many years, it can be seen that the higher the latitude, the more lightning fires are in the forest area. Lightning fires in the northern region account for about $38 \%$ of the total number of forest fires ${ }^{56-58}$.

In order to further observe the atmospheric discharge process in the study area, we installed the EL-EFM1.0 atmospheric electric field instrument and monitoring equipment in the study area to monitor the atmospheric electric field and wildfires in the study area in real time. The wildfire situation in the study area and the atmospheric electric field instrument are shown in Figure 6. 


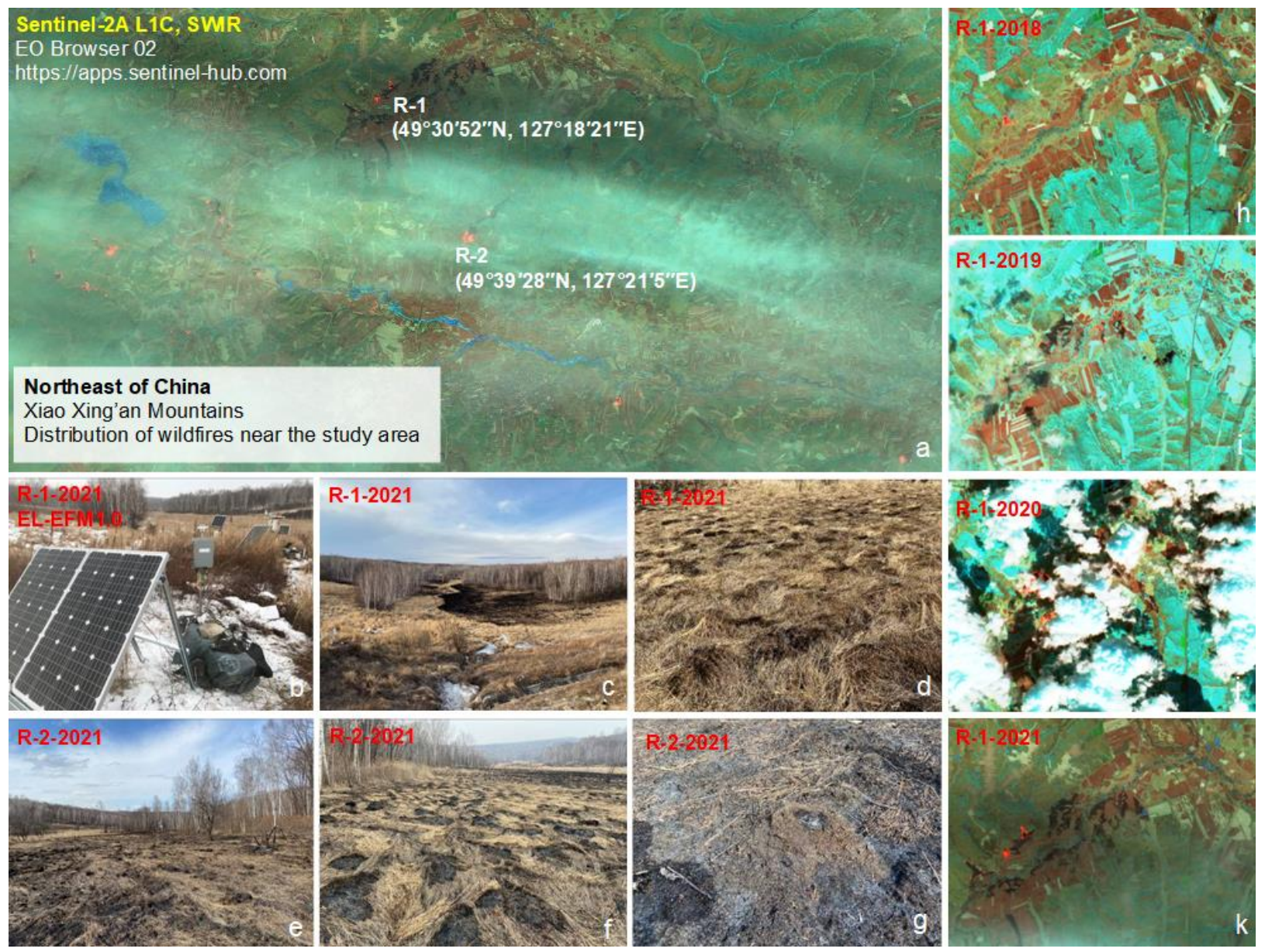

Figure 6. Wildfire in the study area and on-site photos of the atmospheric electric field instrument. a Wildfire near the study area on March 19, 2021 obtained by sentinel 2 (sentinel-2 L1C), in which the red area was wildfire area, and the black area was burned area, b EL-EFM1.0 atmospheric electric field instrument on-site photos, c Burned area in the study area R-1 on March 19, 2021, d Details of the burned area in the study area R-1 on March 19, 2021, e Burned area in the study area R-2 on March 19, 2021, f Details of the burned area in the study area R-2 on March 19, 2021, g Details of the burned area in the study area R-2 on March 19, 2021, h Wildfire in study R-1 on March 22, 2018 obtained by sentinel 2 (sentinel-2 L1C), i Wildfire in study R-1 on March 22, 2019 obtained by sentinel 2 (sentinel-2 L1C), j Wildfire in study R-1 on March 19, 2020 obtained by sentinel 2 (sentinel-2 L1C), k Wildfire in study R-1 on March 19, 2021 obtained by sentinel 2 (sentinel-2 L1C).

It can be seen from the burned area of the study area on March 19, 2021 (Figure 6): A large number of fires appeared near the study area on March 19 (there were basically no fires on the ground near the study area before March 19), and the burning area mostly distributed in low-lying valley swamp areas (Figure 6). Carex tato is distributed in the study area R-1 and R-2. The overall fire situation was mainly incomplete combustion on the surface of carex tato. The root system of carex tato higher than the surface has a higher degree of combustion, while the edge root system of carex tato at the surface water has a lower degree of combustion or even no combustion, in the form of patchy dispersed combustion (Figure 6f). This is because the snow and frozen layer have not completely melted in early spring, and there are many pore channels in the root system of carex tato. Therefore, with the increase of ground temperature, methane gas under the frozen layer is first discharged into the atmosphere from this part of the area. However, because of the low concentration of methane gas in this part, Carex tato is not fully burned and turns black. In addition, there are many similar micro-volcanic areas in the study area (Figure 6g). Carex tato burned heavier and looks gray. This is because the methane gas under the frozen layer breaks through the weak soil layer and the concentration of methane from the pores is higher, which in turn leads to the difference in the degree of combustion. We further obtained the combustion situation near study area R-1 from 2018 to 2021 through Sentinel 2 (SENTINEL-2 L1C) (Figure 6hijk) and obtained the air humidity, soil temperature, soil humidity, pore water pressure and solar radiation in the study area R-1 from March 10 to April 10 each year combined with the meteorological station, as shown in Figure 7. Wildfires occurred in the study area R-1 around March 20, 2018-2021 (Figure 6hijk). It can be seen from Figure 7 that during the period from March 10 to April 10 each year, the daily air humidity changes greatly, and low values appear during the wildfire on March 20. The floating air humidity further strengthens 
atmospheric convection. This promotes the movement of electric charges and strengthens the generation of discharge phenomena in the air (Figure 7abch). During the period from March 10 to April 10, the soil humidity and soil temperature showed an overall upward trend. During this period, the frozen layer and snow gradually melted, and the difference between the total radiation and the net radiation gradually decreased (Figure 7gl), the net radiation on the surface increases, and methane gas gradually moves to the surface (Figure 7deij). The pore water pressure shows a trend of first increasing and then decreasing (Figure $7 \mathrm{fk}$ ). This trend of change is related to the accumulation and release of methane gas under the frozen layer (Figure $7 \mathrm{fk}$ ). In addition, we investigated the distribution of permafrost in the study area and found that the degree of fire is positively correlated with the distribution of permafrost ${ }^{30}$. Therefore, the methane gas stored in the permafrost in the study area plays an important role in the occurrence and spread of wildfires.
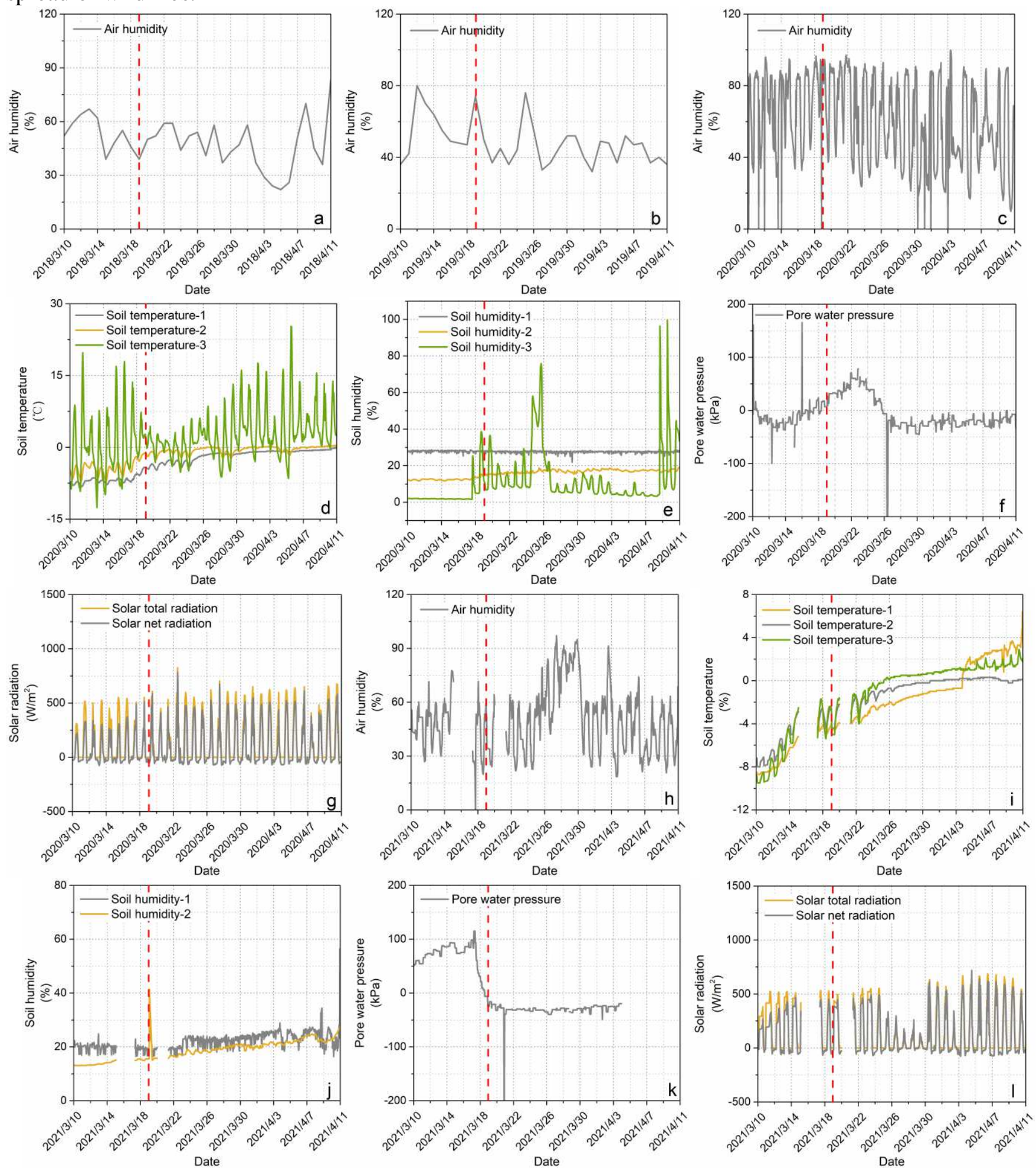

Figure 7. Change curve of air humidity, soil humidity, soil temperature, pore water pressure and solar radiation in the study area R-1 from March 10 to April 10, 2018-2021. a Air humidity in 2018, b Air humidity in 2019, c Air humidity in 2020, d Soil temperature in 2020, e Soil humidity in 2020, f Pore water pressure in 2020, g Solar radiation in 2020, h Air 
humidity in 2021, i Soil temperature in 2021, $\mathbf{j}$ Soil moisture in 2021, $\mathbf{k}$ pore water pressure in 2021, $\mathbf{l}$ Solar radiation in 2021.

We select the atmospheric electric field curve of the study area on February 10, 2021, February 15, 2021, March 15, 2021, March 19, 2021, April 5, 2021, and April 9, 2021 based on changes in air temperature and snow cover, as shown in Figure 8. Comparing the curves on February 10, 2021 and February 15, 2021, it can be seen that when the air temperature is negative in winter, the frozen layer and snow cover on the ground are not melted, and there is relatively little gas exchange and electric charge movement between the ground and the atmosphere, there is a short-term discharge phenomenon with less time. On March 15th, the air temperature entered positive for the first time, the snow and the frozen surface of the ground began to melt, and the methane gas stored under the frozen layer would begin to be released. The gas exchange and electric charge movement between the ground and the atmosphere increased instantly. Due to the influence of snowfall (Figure 9m) between 10-14 o'clock, the gas emission was hindered, and a long-term curve fluctuation appeared. On March 19, the air temperature continued to increase, and air discharges gradually increased and became more concentrated. Combustion occurred in many areas near the study area. There was a wildfire in the study area R-1 between 06:59-15:33 (Figure 9kl), which was related to the air discharge at 10:53-10:58 on March 19 (Figure 8c), snow and high-concentration methane gas released after the melting of the frozen layer is ignited by air discharge. On April 5 and April 8, the air temperature increased, air discharges were more concentrated, and many wildfires continued to occur. We further select the partial curve of the atmospheric electric field change from March 22 to 27, we can see that the atmospheric electric field in the concentrated discharge process mainly includes: positive and negative changes, negative and negative changes, positive and negative positive and negative changes, and negative positive and negative changes, the negative electric field time is longer, which is mainly caused by uneven electric charge distribution caused by electric charge movement, as shown in Figure 9.

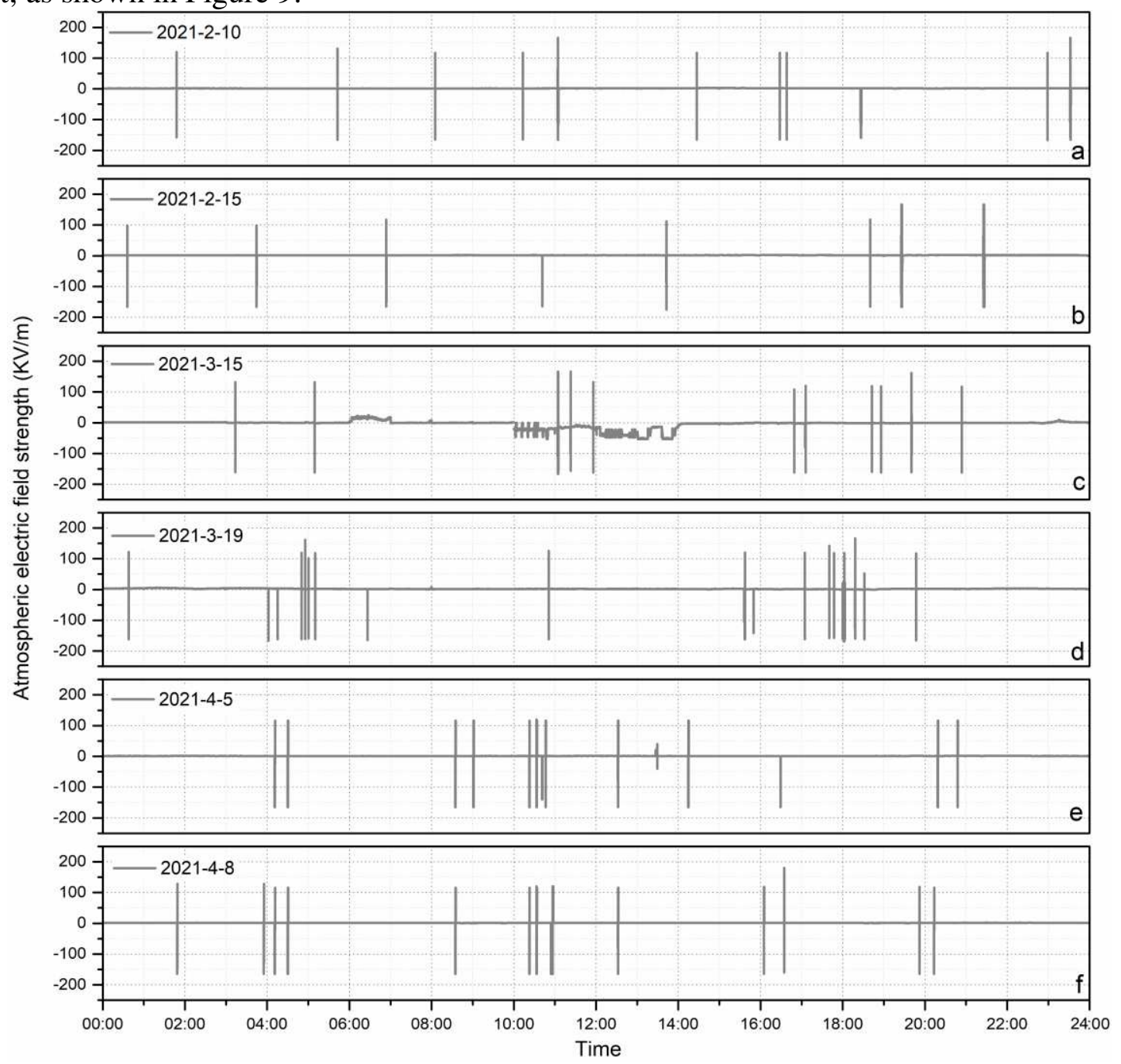

Figure 8. Change curve of atmospheric electric field. a Change curve of the atmospheric electric field on February 10, 2021, the overall air temperature is negative, and the snow and the frozen layer have not melted, $\mathbf{b}$ Change curve of the atmospheric electric field on February 15, 2021, the overall atmospheric temperature is negative, and the snow and the 
frozen layer have not melted., c Change curve of atmospheric electric field on March 15, 2021, the air temperature gradually increases and becomes positive, the snow and the frozen layer gradually melt, among them, there will be snow from 10:00-14:00, d Change curve of atmospheric electric field on March 19, 2021, the air temperature further increased, the snow and frozen layer further melted, and wildfires occurred in the study areas R-1 and R-2, e Air temperature increased on April 5, 2021, and air discharge was more concentrated, f Air temperature increased on April 8, 2021, and air discharge was more concentrated.
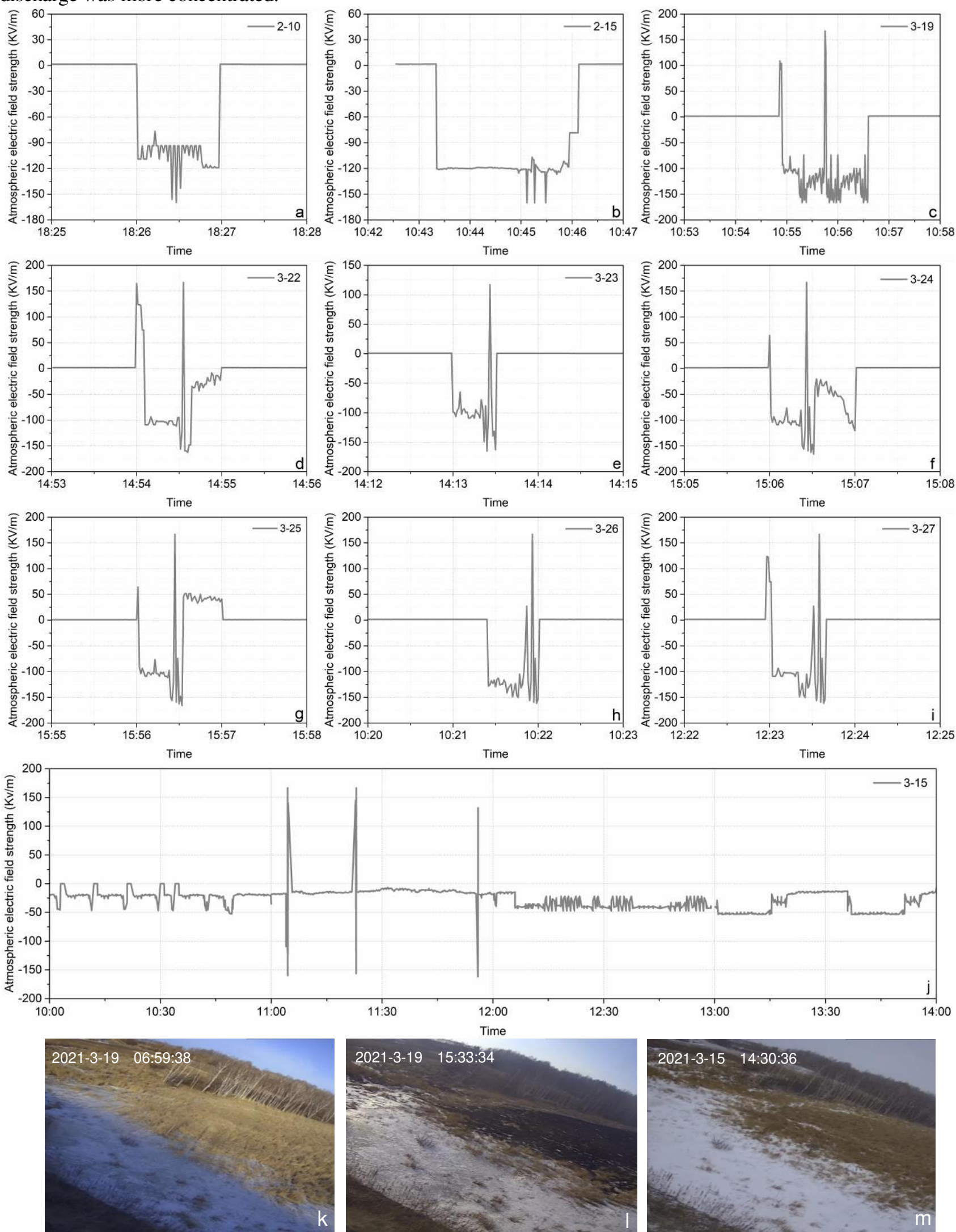

Figure 9. Local change curve of atmospheric electric field change. a Atmospheric electric field changes on February 10, 2021, b Atmospheric electric field changes on February 15, 2021, c Atmospheric electric field changes on March 19, 2021, d Atmospheric electric field changes on March 22, 2021, e Atmospheric electric field changes on March 23, 2021, f Atmospheric electric field changes on March 24, 2021, g Atmospheric electric field changes on March 25, 2021 h Atmospheric electric field changes on March 26, 2021, i Atmospheric electric field changes on March 27, 2021, j 
Atmospheric electric field changes on March 15, 2021, the air temperature gradually increased to a positive value that day, and the snow began to melt, there was snowfall from 10:00 to 14:00, and the atmospheric electric field fluctuated significantly, k On-site photos in study area R-1 at 06:59:38 on March 19, 2021, l On-site photos in study area R-1 at 15:33:34 on March 19, 2021, it can be seen that wildfires occurred between 06:59:38-15:33:34. m On-site photos in study area R-1 at 14:30:36 on March 15, 2021, a large amount of snow appeared on the site after the snowfall from 10:00-14:00.

In addition, higher mixed gas pressure and methane gas content will reduce the thermal spontaneous combustion temperature of methane gas within a certain range ${ }^{30,59}$, thereby promoting the thermal spontaneous combustion of methane gas. When methane gas combines with aerosols (such as dust, sea salt, sulfate, black carbon and other atmospheric particles), the warming potential of methane is greater $^{60-62}$. Since the presence of aerosol will further improve the influence of methane gas on atmospheric warming and then increase the occurrence of wildfire, the permafrost area will gradually degenerate, and the methane gas released will become an important inducement factor of wildfire in permafrost area.

\section{Establishment of conceptual model}

Based on the above study, a conceptual model of methane emissions and their impact on wildfires in permafrost region is established (Figure 10). The structure of soil layers at different depths can be simplified from top to bottom: thicker peat soil, permafrost (mainly gravel sand clay, etc.), gravel-bearing mudstone layer, and certain reserves of methane hydrate in the permafrost layer, the distribution is relatively uneven. The permafrost layer is gradually degraded, and the methane hydrate stored in it will be disturbed and decomposed to form high-concentration methane gas. This part of the gas will gradually migrate to the surface under the pressure gradient and accumulate under the frozen layer of the surface. The main sources of methane gas on the surface of the study area include the action of microorganisms and the decomposition of methane hydrate in the permafrost. In the spring, the methane gas accumulated under the frozen layer has a high pressure and high concentration. The rapid upward movement of gas molecules will cause friction with the soil particles, causing the methane molecules to be positively charged and promoted by the negative charge at the bottom of the near-surface cloud layer and the pore pressure of the soil, and then produces a discharge phenomenon, interacts with the external environment (increased temperature and decreased humidity), finally causes the high concentration of methane gas in the air to be ignited, which then spreads to form large-scale wildfires and forest fires.

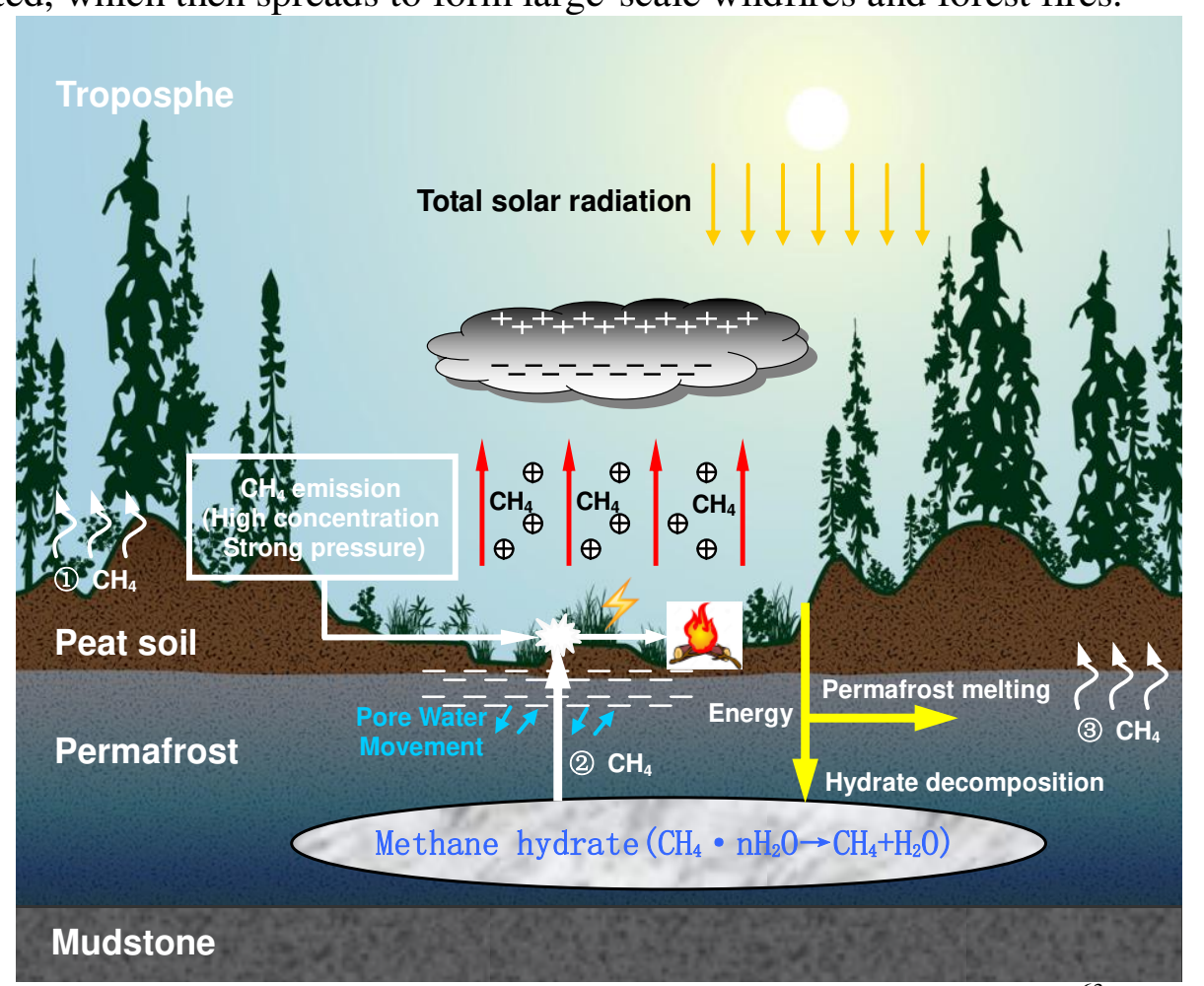

Figure 10. Conceptual model of methane emissions and its impact on wildfires in permafrost ${ }^{63}$. The top of the soil layer is peat soil with a certain thickness, the bottom is a permafrost layer and contains a certain amount of methane hydrate, and the bottom layer is mudstone.

\section{Discussion and conclusions}

Affected by environmental factors, the thickness of the permafrost in the northern part of the Xiao 
Xing'an Mountains in Northeast China is gradually shrinking ${ }^{64}$, and organic matter and methane hydrate stored in the frozen soil are gradually entering the atmosphere in the form of methane gas. The annual maximum methane concentration on the surface of methane gas emission occurs every spring (March to May). The methane gas produced by the decomposition of the metastable methane hydrate and the deep stable methane hydrate stored in the permafrost ice layer is the main source of high-concentration methane gas entering the surface at this stage ${ }^{30}$. In the spring, when the frozen layer on the surface of the permafrost gradually melts, the high-concentration, high-pressure methane gas accumulated under the frozen layer will be quickly released into the atmosphere. In the process of rapid movement of methane gas in the soil, it will rub against the soil particles, and the extranuclear electrons will get rid of the bondage, causing the positively charged methane gas to gradually enter the atmosphere. With the gradual release of methane gas, the positive charge released from the ground gradually increases and the positive charge flow column will gradually increase and strengthen, so as to contact the negative charge in the cloud layer near the ground to form a discharge channel and strengthen the discharge phenomenon. In this process, there are more positive charges on the ground, so the atmospheric electric field near the ground is mainly positive. With the release of methane gas, the positive charge gradually enters the atmosphere, and the positive charge in the atmosphere gradually increases. The positively charged methane and the water molecules in the atmosphere near the ground form positively charged aerosols, and the positive charge on the ground gradually decreases. The atmospheric electric field near the ground is mainly negative. Compared with air, methane gas has higher flammability and electrical conductivity, so the continuous near-ground atmospheric discharge phenomenon will ignite the methane gas. In addition, higher mixed gas pressure and methane gas content will reduce the thermal spontaneous combustion temperature of methane gas within a certain range, thereby promoting the thermal spontaneous combustion of methane gas. When methane gas combines with aerosols (such as dust, sea salt, sulfate, black carbon and other atmospheric particles), the warming potential of methane is greater. Since the presence of aerosol will further improve the influence of methane gas on atmospheric warming and then increase the occurrence of wildfire.

Lightning played a key role in the recent forest fires in northern North America near the Arctic tree line. The effect of the increased lightning is considered to be specific to the lightning-wildfire feedback. The study found that ${ }^{21}$ convective available potential energy $(86 \pm 22 \%)$ and rainfall $(17 \pm 2 \%)$ increased, resulting in an increase of $112 \pm 38 \%$ in summer lightning at the end of this century (2081-2100) in permafrost regions. Maracaibo Lake is one of the largest lightning generators in the world. Maracaibo Lake is surrounded by towering mountain peaks, which helps to form a conflict between warm and cold air, which promotes the development of thunderstorms. The collision between the cool breeze flowing from the mountains at night and the warm tropical waters of the lake produces about 297 nights of thunderstorms on the lake every year ${ }^{75}$. In addition to these reasons, it is also believed that the unique concentration and intensity of lightning here can be attributed to the large amount of methane on the ground below the area. Maracaibo Basin is located on one of the largest oil fields in the world, which produces large amounts of methane gas. Theoretically, this methane may seep into the atmosphere and increase electrical conductivity, thereby bringing additional benefits to thunderstorms and lightning. In addition, calculating the current annual average burned area of each lightning, the ratio of the tundra area is lower than that of the boreal forest. Using the ratios obtained by two different estimation methods, the burned area increased by $158 \%$ and $570 \%$, respectively. When vegetation feedback is considered, the estimated value is larger. However, due to changing climate changes the forest ecosystem, part of the forest is converted from carbon sinks into carbon sources, and a large amount of methane gas is released from the withered trees ${ }^{65-68}$. For coastal forests, this transformation is even more obvious. Studies have shown that seawater exposure increases the salinity of the soil around submerged trees, leading to increased methane content in the trunk and soil, and lower oxygen content. Trees with higher wood density have higher stem methane concentrations ${ }^{65,66}$. The release of methane gas gradually accumulated in the trees may be charged after friction and form a local electric field. As the electric potential increases, the methane gas will eventually be ignited by the electric field breakdown discharge and eventually form a forest fire. For example, the Sierra Nevada Mountains in California have experienced a series of catastrophic wildfires in recent decades ${ }^{69,70}$, which coincided with the warming of spring and summer caused by climate change ${ }^{71,72}$. From the end of the winter of 2019 to the summer of 2020, devastating fires broke out in large areas of eastern Australia, causing huge losses of life and property. Although 
flammable vegetation types and seasonally distinct climate conditions make eastern and northern Australia one of the most fire-prone areas in the world, the fires from 2019 to 2020 are still unprecedented in history, which shows that under the influence of climate warming, Australia's fire risk may be underestimated $^{73,74}$. For the increasing wildfires around the world, methane gas from different sources may be an important factor that cannot be ignored.

\section{Method}

\section{Meteorological station observation}

This paper adopts the meteorological monitoring system (http://www.qixiangshuju.com) and the ground soil physical parameter monitoring system (http://www.hzjly.cn) to monitor the meteorological data in real time on site. In January 2009 , monitoring system was set up in study area R-1 (49 $30^{\prime} 52^{\prime \prime} \mathrm{N}$, $127^{\circ} 18^{\prime} 21^{\prime \prime} \mathrm{E}$, Altitude $278 \mathrm{~m}$ ), and in January 2019, monitoring system was set up in study area R-2 $\left(49^{\circ} 39^{\prime} 28^{\prime \prime} \mathrm{N}, 127^{\circ} 21^{\prime} 5^{\prime \prime} \mathrm{E}\right.$, Altitude $\left.229 \mathrm{~m}\right)$. The meteorological station model is GD24-YCXQ, mainly composed of data acquisition host, data analysis system, data transmission system, Internet of Things sensors, GPRS wireless transmission system, solar power supply system, etc. As the value of the meteorological element changes, the output power of each sensor element also changes, and the data collector controlled by the CPU collects in real time. After linearization and quantification processing, the conversion from process quantity to element quantity is realized, and then the data is filtered to obtain the value of each meteorological element. The ambient temperature of meteorological station is $-30^{\circ} \mathrm{C} \sim 70^{\circ} \mathrm{C}$, and the data storage is $64 \mathrm{G}$, which is stored every hour. It mainly includes surface methane concentration sensor (QT21-BX80-CH4) and air temperature sensor (GD51-KWSY). Methane concentration sensors $\left(\mathrm{QT} 21-\mathrm{BX} 80-\mathrm{CH}_{4}\right)$, the measurement range of is $0 \sim 1000 \mathrm{ppm}$, the measurement accuracy is $\pm 1 \%$ (F.S.), the resolution is $0.1 \mathrm{ppm}$, and the temperature range is $-25^{\circ} \mathrm{C} \sim 45^{\circ} \mathrm{C}$. Soil pore water pressure sensor(KXR-3034), is a vibrating wire pore water pressure sensor, the measurement range is $-1.0 \sim 1.0 \mathrm{MPa}$, the measurement accuracy is $\pm 0.05 \%$ (F.S.), the resolution is $0.01 \mathrm{kPa}$, and the temperature range is $-25^{\circ} \mathrm{C} \sim 60^{\circ} \mathrm{C}$. Air temperature sensors (GD51-KWSY), the measurement range is $-30^{\circ} \mathrm{C} \sim 120^{\circ} \mathrm{C}$, the measurement accuracy is $\pm 0.2^{\circ} \mathrm{C}$, the resolution is $0.1{ }^{\circ} \mathrm{C}$, and the working temperature is $-40^{\circ} \mathrm{C} \sim 75^{\circ} \mathrm{C}$. The ground soil physical parameter monitoring system uses soil pore water pressure sensor (KXR-3034) and soil temperature sensor (HJ6-FM-TWB) to monitor related parameters. Pore water pressure sensor uses 4 20mA output and the output current signal can be converted into the actual pore water pressure value. The KXR-3034 vibrating wire pore water pressure calculation formula is shown in (4). Where $P$ is the pressure value of the measured pore water pressure sensor (MPa), $K$ is the sensitivity coefficient of the pore water pressure sensor $\left(\mathrm{MPa} / \mathrm{Hz}^{2}\right.$, the values are $\left.1.229,1.181,1.001\right), f_{0}$ is the initial frequency value of the pore water pressure sensor (the values are 1684.3, 1436.3, and 1207.6), $f_{\mathrm{i}}$ is the working frequency value of the pore water pressure sensor.

$$
P=K\left(f_{\mathrm{i}}^{2}-f_{0}^{2}\right)
$$

Soil temperature sensor(HJ6-FM-TWB), its measurement range is $-30^{\circ} \mathrm{C} \sim 120^{\circ} \mathrm{C}$, the measurement accuracy is $\pm 0.2^{\circ} \mathrm{C}$, the resolution is $0.1^{\circ} \mathrm{C}$, the working temperature is $-40^{\circ} \mathrm{C} \sim 75^{\circ} \mathrm{C}$. The real-time monitoring system includes the meteorological data monitoring system (http://www.qixiangshuju.com) and the soil data monitoring system (http://www.hzjly.cn). In addition, in addition to the methane concentration sensor, we also used the SKZ1050- $\mathrm{CH}_{4}$ handheld methane detector to detect the methane concentration on the surface of the study area. The measurement range is 0 100\% LEL, the measurement accuracy is $\pm 2 \%$ (F.S.), and the resolution is $0.1 \%$ LEL.

\section{Sentinel-2 L1C satellite image}

In this paper, the satellite images (https://apps.sentinel-hub.com/eo-browser/) provided by sentinel 2 L1C are used to track 2018-2020 wildfires in Northeast China and East Siberia. Sentinel-2 L1C is the atmospheric apparent reflectance product after orthorectification and sub-pixel geometric precision correction, and is composed of UTM / WGS84 projection orthophoto image. The L1C product image is projected to the cartographic coordinates using the Digital Elevation Model (DEM) during orthorectification, which is the reflectance image of the Top of Atmosphere (TOA). At the same time, the relevant information of the radiation measurement processed as each pixel of the L1C product is recorded. According to the resolution of different spectral bands, L1C products are re-sampled with fixed ground sampling distance (Ground Sampling Distance, GSD) of 10, 20 and $60 \mathrm{~m}$.

\section{EL-EFM1.0 atmospheric electric field instrument}


In this paper, the EL-EFM1.0 atmospheric electric field instrument is used to monitor the atmospheric electric field within a radius of $15 \mathrm{~km}$ near the study area in real time. Among them, the sensitivity of the atmospheric electric field instrument is $<50 \mathrm{~V} / \mathrm{m}$, the electric field resolution is $<5 \mathrm{~V} / \mathrm{m}$, the response time is $1 \mathrm{~s}$, the working temperature: $-40^{\circ} \mathrm{C} \sim 70^{\circ} \mathrm{C}$, and the working humidity: $0 \% \sim 100 \%$.

\section{Acknowledgements}

We thank for National Natural Science Foundation of China (41641024) for providing financial support and Field scientific observation and research station of the Ministry of Education - Geological environment system of permafrost area in Northeast China (FSSE-PFNEC)

\section{Author contributions}

S.W., X.Z.C., G.Y. designed research and wrote the main manuscript text, X.Z.C., Z.C.C. collated data, S.W., X.Z.C., G.Y. installed field sensors. All authors reviewed the manuscript.

\section{References}

1. Schuur E. A. G., McGuire A. D., Schädel C. Climate change and the permafrost carbon feedback. Nature 530, 171-179 (2015).

2. Dallimore S. R., Collett T. S. Intrapermafrost gas hydrates from a deep core hole in the Mackenzie Delta, Northwest Territories, Canada. Geology 23, 527-530 (1995).

3. Yakushev V. S., Chuvilin E. M. Natural gas and gas hydrate accumulations within permafrost in Russia. Cold Regions Science and Technology 31, 189-197 (2000).

4. Yakushev V. S. Natural Gas and Gas Hydrates in Permafrost. Moscow, VNIIGAZ, 192p (2009). (In Russian)

5. Yakusheva V. S., Semenova A. P., Bogoyavlenskyb V. I. et al. Experimental modeling of methane release from intrapermafrost relic gas hydrates when sediment temperature change. Cold Regions Science and Technology 149, 46-50 (2018).

6. IPCC. Special Report on the Ocean and Cryosphere in a Changing Climate. Contribution of Working Group I and Working Group II to the Sixth Assessment Report of the Intergovernmental Panel on Climate Change. Morocco (2019).

7. Burke S. A., Wik M., Lang A. et al. Long-Term Measurements of Methane Ebullition From Thaw Ponds. Journal of Geophysical Research-Biogeosciences 124, 2208-2221 (2019).

8. Yun H., Wu Q., Zhuang Q. et al. Consumption of atmospheric methane by the Qinghai-Tibet Plateau alpine steppe ecosystem. Cryosphere 12, 2803-2819 (2018).

9. Reagan M. T., Moridis G. J. Oceanic gas hydrate instability and dissociation under climate change scenarios. Geophysical Research Letters 34, L22709 (2007).

10. Dickens G. R. Down the Rabbit Hole: toward appropriate discussion of methane release from gas hydrate systems during the Paleocene-Eocene thermal maximum and other past hyperthermal events. Climate of the Past 7, 831-846 (2011).

11. Berndt C., Feseker T., Treude T. Temporal constraints on hydrate-controlled methane seepage off svalbard. Science 343, 284-287 (2014).

12. Sukhinin A. I., French N. H. F., Kasischke E. S. et al. AVHRR based mapping of fires in Russia: new products for fire management and carbon cycle studies. Remote Sens Environ 93, 546-564 (2004).

13. Tan Z., Tieszen L. L., Zhu Z. et al. An estimate of carbon emissions from 2004 wildfires across Alaskan Yukon River Basin. Carbon Balance Manag 2, 12 (2007).

14. Flannigan M., Stocks B., Turetsky M. et al. Impacts of climate change on fire activity and fire management in the circumboreal forest. Glob Chang Biology 15, 549-560 (2009).

15. Ponomarev E. I., Ponomareva T. V. The effect of postfire temperature anomalies on seasonal soil thawing in the permafrost zone of central siberia evaluated using remote data. Contemporary Problems of Ecology, 11, 420-427 (2018).

16. Kharuk V. I., Ponomarev E. I. Spatiotemporal characteristics of wildfire frequency and relative area burned in larch-dominated forests of central siberia. Russian Journal of Ecology. 48, 507-512 (2017).

17. Abaimov A. P., Sofronov M. A. The main trends of post-fire succession in near-tundra forests of central Siberia. Fire in Ecosystems of Boreal Eurasia. 48, 372-386 (1996). 
18. Gorbachev V. N., Popova E. P. Fires and soil formation. Fire in Ecosystems of Boreal Eurasia. 48, 331-336 (1996).

19. Sofronov M.A., Volokitina A.V., Kajimoto T., et al. Zonal peculiarities of forest vegetation controlled by fires in northern Siberia. Eurasian Journal of Forest Research. 1, 51-59 (2000).

20. Schädel C., Bader M. K. F., Schuur E. A. G. et al. Potential carbon emissions dominated by carbon dioxide from thawed permafrost soils. Nature Climate Change 6, 950-953 (2016).

21. Chen Y., Romps M. D., Seeley T. J., et al. Future increases in Arctic lightning and fire risk for permafrost carbon. Nature Climate Change, https://doi.org/10.1038/s41558-021-01011-y (2021).

22. Finney L. D. Lightning threatens permafrost. Nature Climate Change, https://doi.org/10.1038/s41558-021-01016-7 (2021).

23. Veraverbeke S., Rogers B. M., Goulden M. L., et al. Lightning as a major driver of recent large fire years in North American boreal forests. Nature Climate Change 7, 529-534 (2017).

24. Witze A. The Arctic is burning like never before - and that's bad news for climate change. Nature 585, 336-337 (2020)

25. Price C. Lightning applications in weather and climate research. Surveys in Geophysics. 34, 755-767 (2013).

26. Williams E. R. Lightning and climate: a review. Atmospheric Research. 76, 272-287 (2005).

27. Christian H. J. et al. Global frequency and distribution of lightning as observed from space by the Optical Transient Detector. Journal of Geophysical Research Atmospheres 102, 1-15(2003).

28. Albrecht, R. I., Goodman, S. J., Buechler, D. E., Blakeslee, R. J. \& Christian, H. J. Where are the lightning hotspots on Earth? Bull. Am. Meteorol. Soc. 97, 2051-2068 (2016).

29. Kim Y., Tanaka N. Effect of forest fire on the fluxes of CO2, CH4 and N2O in boreal forest soils, interior Alaska. Journal of Geophysical Research-Atmospheres 108, D18154 (2003).

30. Shan W., Xu Z. C., Guo Y., et al. (2020b). Geological methane emissions and wildfire risk in the degraded permafrost area of the Xiao Xing'an Mountains, China. Scientific Reports 10, 21297.

31. Jaroslav O., Sebastian W., Annett B. et al. Northern Hemisphere permafrost map based on TTOP modelling for 2000-2016 at $1 \mathrm{~km}^{2}$ scale. Earth-Science Reviews, 193, 299-316 (2019).

32. Zhou Y. W., et al. Frozen Soil in China. Beijing: Science Press (2000). (In Chinese)

33. Wang C. J., Shan M. N., Hu Z. G., et al. Multi-spectral remote sensing based land surface temperature retrieval and isolated permafrost zone segmentation. Infrared and Laser Engineering. 44, 1390-1396 (2015) (In chinese).

34. Wei Z., Jin H. J., Zhang J. M., et al. Prediction of permafrost change in northeast China under climate change. Science China: Earth Science 41, 74-84 (2011). (In Chinese)

35. Sun G. Y. Discussion on the symbiotic mechanisms of swamp with permafrost — Taking Da-Xiao Hinggan Mountains as examples. Journal of Glaciology and Geocryology 22, 309-316 (2000). (In Chinese)

36. Guo D. X., Wang S. L., Lu G. W., et al. Division of permafrost regions in Daxiao Hinggan Ling northeast China. Journal of Glaciology and Geocryology 3, 1-9 (1981). (In Chinese)

37. Jin H. J., Yu Q. H., Lü L., et al. Degradation of permafrost in the Xing'anling Mountains, northeastern China. Permafrost and Periglacial Processes 18, 245-258 (2007).

38. Zuo H. C., Lu S. H., Hu Y. Q. Variations trend of yearly mean air temperature and precipitain in China in the last 50 years. Plateau Meteorology 23, 238-244 (2004).

39. Chen L. X., Zhou X. J., Li W. L., et al. Characteristics of the climate change and its formation mechanism in China in last 80 years. Acta Meteorologica Sinica 62, 634-646 (2004).

40. Ren G. Y., Guo J., Xu M. Z., Chu Z., Zhang L., Zou X. et al. Climate changes of China's mainland over the past half century. Acta Meteorologica Sinica 63, 942-956 (2005).

41. He W., Bu R. C., Xiong Z. P., et al. Characteristics of temperature and precipitation in Northeastern China from 1961 to 2005. Acta ecologica sinica. 33, 519-531 (2013).

42. Wei Z., Jin H. J., Luo C. X., et al. Characteristics of atmospheric environmental changes of permafrost in northeastern China in 50 years. Journal of Lanzhou University. Natural Science 44, 39-42 (2008).

43. Shu L. F., Wang M. Y., Tian X. R., et al. The fire environment mechanism of lightning fire formed for daxing'an mountains. Scientia Silvae Sinicae 39, 39-42 (2008). (In Chinese) 
44. Kolmasova I., Santolik O., Kaspar P., et al. First Observations of Elves and Their Causative Very Strong Lightning Discharges in an Unusual Small-Scale Continental Spring-Time Thunderstorm. Journal of Geophysical Research-Atmospheres. 126, e2020JD032825 (2020).

45. Taylor A. R., Ecological aspects of lightning in forests. Proceedings Tall Timbers Fire Ecology Conferences. 13, 455-482 (1974).

46. Feng J. W., Shen H., Liang D. Study on the occurrence law of forest lightning fire. Acta Scientiarum Naturalium Universitatis Sunyatseni. 6, 1-8 (2020). (In Chinese)

47. Yang J., He Q. J., Zhong L. H. R esearch Progress of Lightning Discharges Between Thundercloud Top and Lower Ionosphere. Meteorological and Environmental Sciences. 41:117-127 (2018). (In Chinese)

48. Zhang J. Y., Coote M. L., Clampi S. Electrostatics and Electrochemistry: Mechanism and Scope of Charge-Transfer Reactions on the Surface of Tribocharged Insulators. Journal of the American Chemical Society 143, 3019-3032 (2021).

49. Harper J. S. M., Cimarelli C., Dufek J., et al. Inferring Compressible Fluid Dynamics From Vent Discharges During Volcanic Eruptions. Geophysical Research Letters 45, 7226-7235 (2018).

50. Zhu Y., Jiang S. Y. Analysis of Electrostatic Signal in Gas Solid Two Phase Flow. Computer Simulation 33, $192-196$ (2016). (In Chinese)

51. Hasegawa T., Komori C., Matsuyama T. Microscale gap breakdown induced by toner triboelectrification. Advanced Powder Technology 26, 42-48 (2015).

52. Pan S. H., Yin N. A., Zhang Z. N. Time- \& Load-Dependence of Triboelectric Effect. Scientific Reports 8, 1-9 (2018).

53. Grosshans H., Papalexandris M. V. Direct numerical simulation of triboelectric charging in particle-laden turbulent channel flows. Journal of Fluid Mechanics 818, 465-491 (2017).

54. Zhang X. L., Zheng Y. B., Wang D. A., et al. Liquid-solid contact triboelectrification and its use in self-powered nanosensor for detecting organics in water. Nano Energy, 30, 321-329 (2016).

55. Lin Q. Z., Zhu J. P., Wang Q. A. Study on forest fire caused by lightning strike. Fire Safety Science, 8, 15-21 (1999). (In Chinese)

56. Zhao J. H., Kang X. G., Guo G. M., et al. Spatial and temporal distribution of lightning fire in Northeast China based on LIS/OTD grid data. Chinese Journal of Ecology 28, 715-720 (2009). (In Chinese)

57. Zheng H. N. Forest fire in Northeast China. Northeast Forestry University Press, Harbin (2001). (In Chinese)

58. Shu L. F. The fire environment mechanism of lightning fire formed for daxing'an mountains. Scientia Silvae Sinicae 39, 94 -99 (2003). (In Chinese)

59. Williams F. A. Combustion-Theory. London: Taylor \& Francis Inc (1994).

60. Katharine S. Aerosols make methane more potent, nature 1-3 (2009)

61. Shindell D.T. et al. Improved Attribution of Climate Forcing to Emissions. Science 326, 716-718 (2009).

62. Arneth A. et al. Clean the Air, Heat the Planet? Science 326, 672-673 (2009).

63. Strack M., Hayne S., Lovitt J. et al. Petroleum exploration increases methane emissions from northern peatlands. Nature Communications 10, 2804 (2019).

64. Guo Y., Shan W., Zhang C. C., et al. (2020). Monitoring of permafrost degradation along the Bei'an-Heihe Expressway in China. Bulletin of Engineering Geology and the Environment. 16, 1-10 (2020).

65. Underwood, E. Why mountainous upland forests emit so much methane. Journal of Geophysical Research: Biogeosciences 98 (2017).

66. Sidder, A. Coastal flooding enhances methane buildup in forests. Journal of Geophysical Research: Biogeosciences 102 (2021).

67. Zhuang J. J., Tian Y. Dynamics of methane and other greenhouse gases flux in forest ecosystems in China. Journal of Environmental Science and Health Part A-Toxic/Hazardous Substances \& Environmental Engineering 56, 241-247 (2020).

68. Mazzola V., Perks M. Smith J., et al. Seasonal patterns of greenhouse gas emissions from a forest-to-bog restored site in northern Scotland: Influence of microtopography and vegetation on carbon dioxide and methane dynamics. 
European Journal of Soil Science 16, 1-22 (2020).

69. Miller J. D., Safford H. Trends in wildfire severity: 1984 to 2010 in the Sierra Nevada, Modoc Plateau, and southern Cascades, California, USA. Fire Ecology. 8, 41-57 (2012).

70. Peterson D. A., Hyer E. J., Campbell J. R., et al. The 2013 Rim Fire: Implications for predicting extreme fire spread, pyroconvection, and smoke emissions. Bulletin of the American Meteorological Society. 96, 229-247 (2015).

71. Westerling A. L., Gershunov A., Brown T. J., et al. Climate and wildfire in the western United States. Bulletin of the American Meteorological Society. 84, 595-604 (2003).

72. Westerling A. L., Hidalgo H. G., Cayan D. R., et al. Warming and earlier spring increase western U.S. forest wildfire activity. Science, 313, 940 (2006).

73. Chen B., Jin Y. F. Scaduto E., et al. Climate, Fuel, and Land Use Shaped the Spatial Pattern of Wildfire in California's Sierra Nevada. Journal of Geophysical Research Biogeosciences. 126, 1-18 (2021).

74. Shi G., Yan H., Zhang W. C., et al. Rapid warming has resulted in more wildfires in northeastern Australia. Science of the Total Environment. 771, 144888 (2021).

75. Perkins S. You're more likely to get struck by lightning here than anywhere else on Earth. Science, doi:10.1126/science.aal0561 (2016). 


\section{Figures}

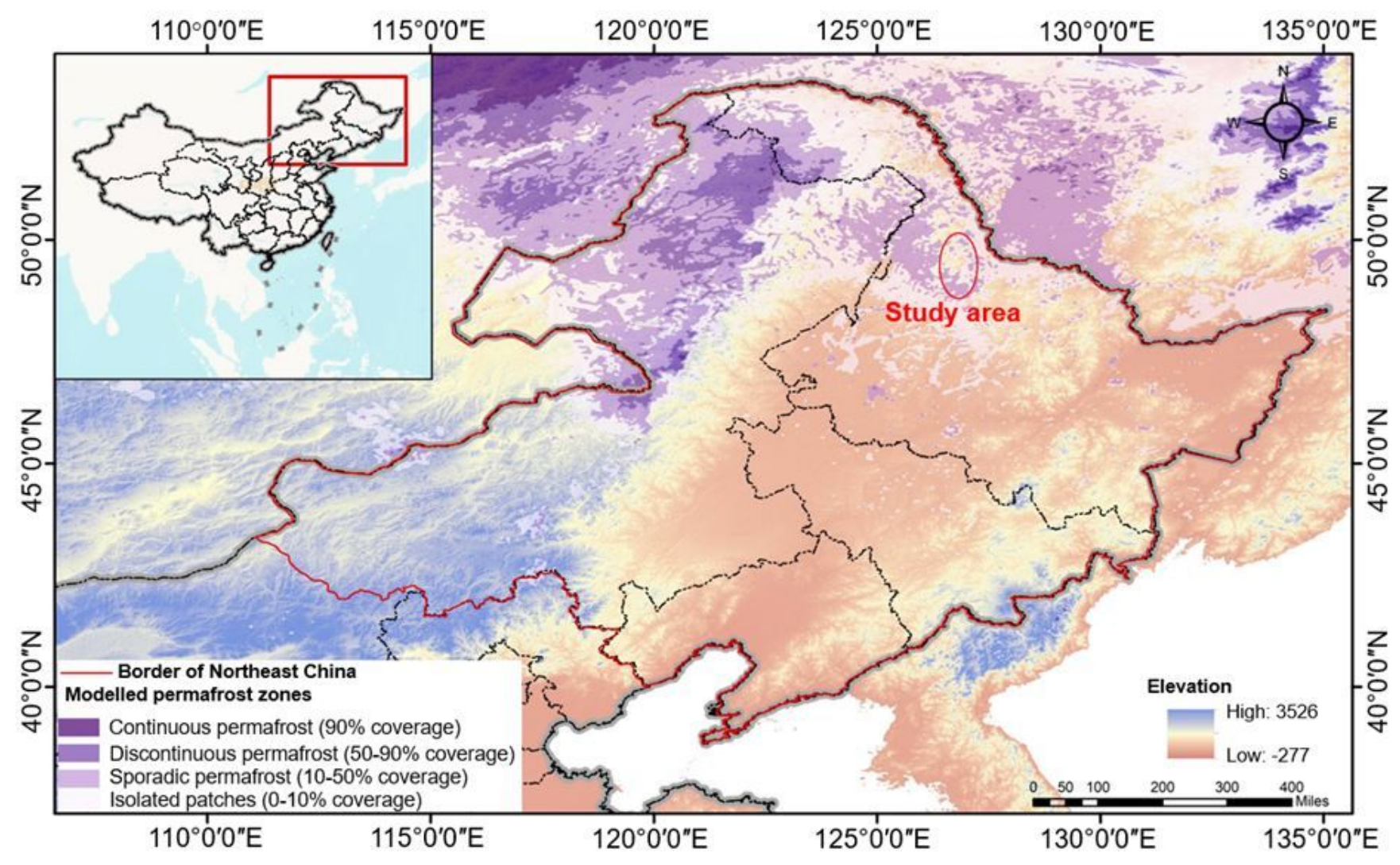

\section{Figure 1}

Distribution map of permafrost in Northeast China and location of the study area, according to the degree of permafrost coverage, divided into continuous permafrost ( $>90 \%)$, discontinuous permafrost (50-90\%), sporadic permafrost (10-50\%), isolated patches (0-10\%); data from Jaroslav 0. et al. (2019)30,31. Note: The designations employed and the presentation of the material on this map do not imply the expression of any opinion whatsoever on the part of Research Square concerning the legal status of any country, territory, city or area or of its authorities, or concerning the delimitation of its frontiers or boundaries. This map has been provided by the authors. 


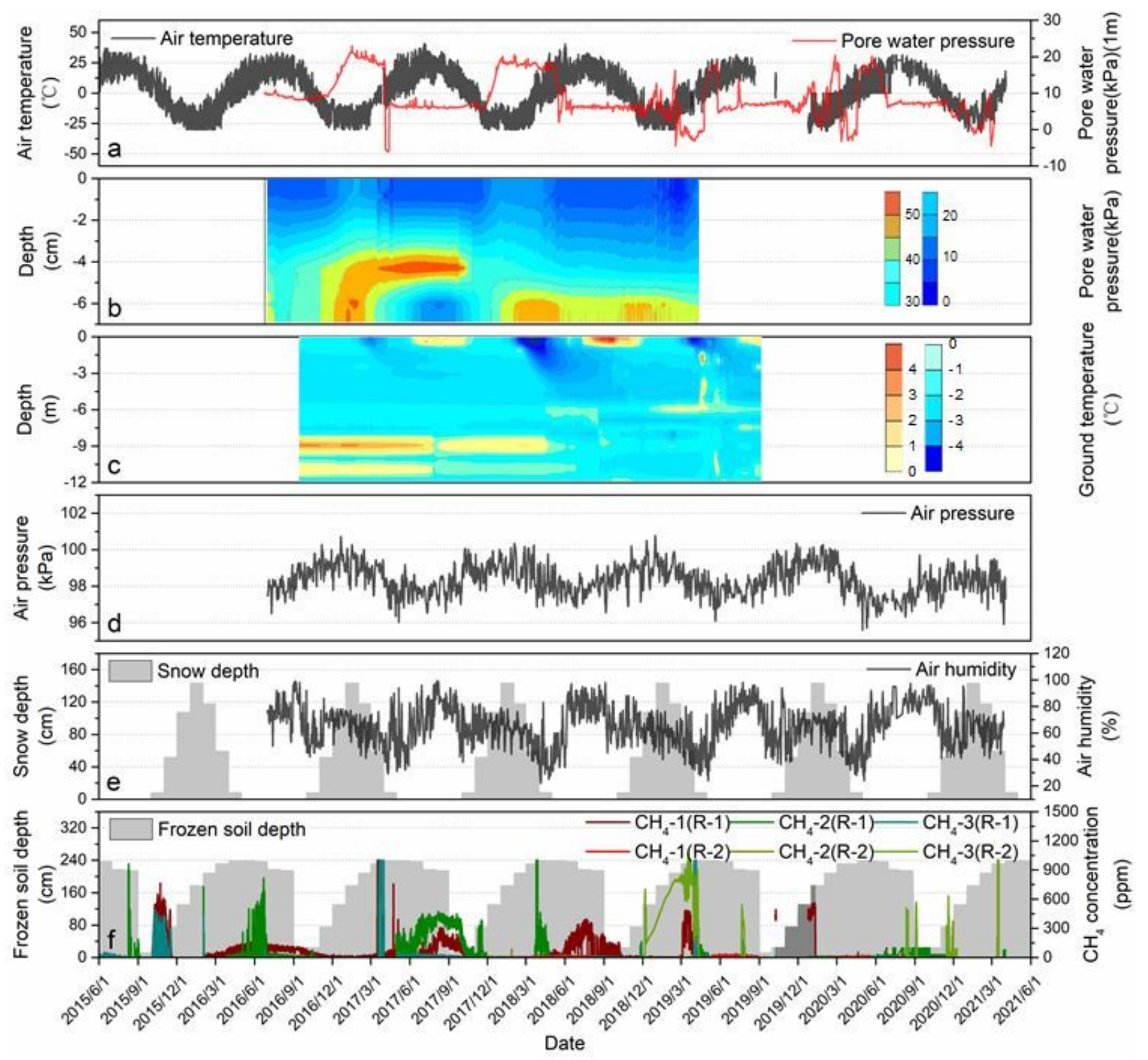

Figure 2

Change of monitoring factors in study area R-1 and R-2. a Pore water pressure at depth of $1 \mathrm{~m}$ underground and air temperature in study area $\mathrm{R}-1, \mathrm{~b}$ Isoline map of soil pore water pressure at depth of $0-7 m$ in study area R-1, c Isoline map of ground temperature at $0-12 m$ at depth of R-1 in study area R-1, d Atmospheric pressure in the study area $\mathrm{R}-1$, e Atmospheric relative humidity and average snow cover thickness in the study area R-1, $f$ Surface methane concentration and the monthly maximum active layer thickness (frozen soil depth, distance from the surface to the upper limit of frozen soil) in study area R-1 and R-2. 


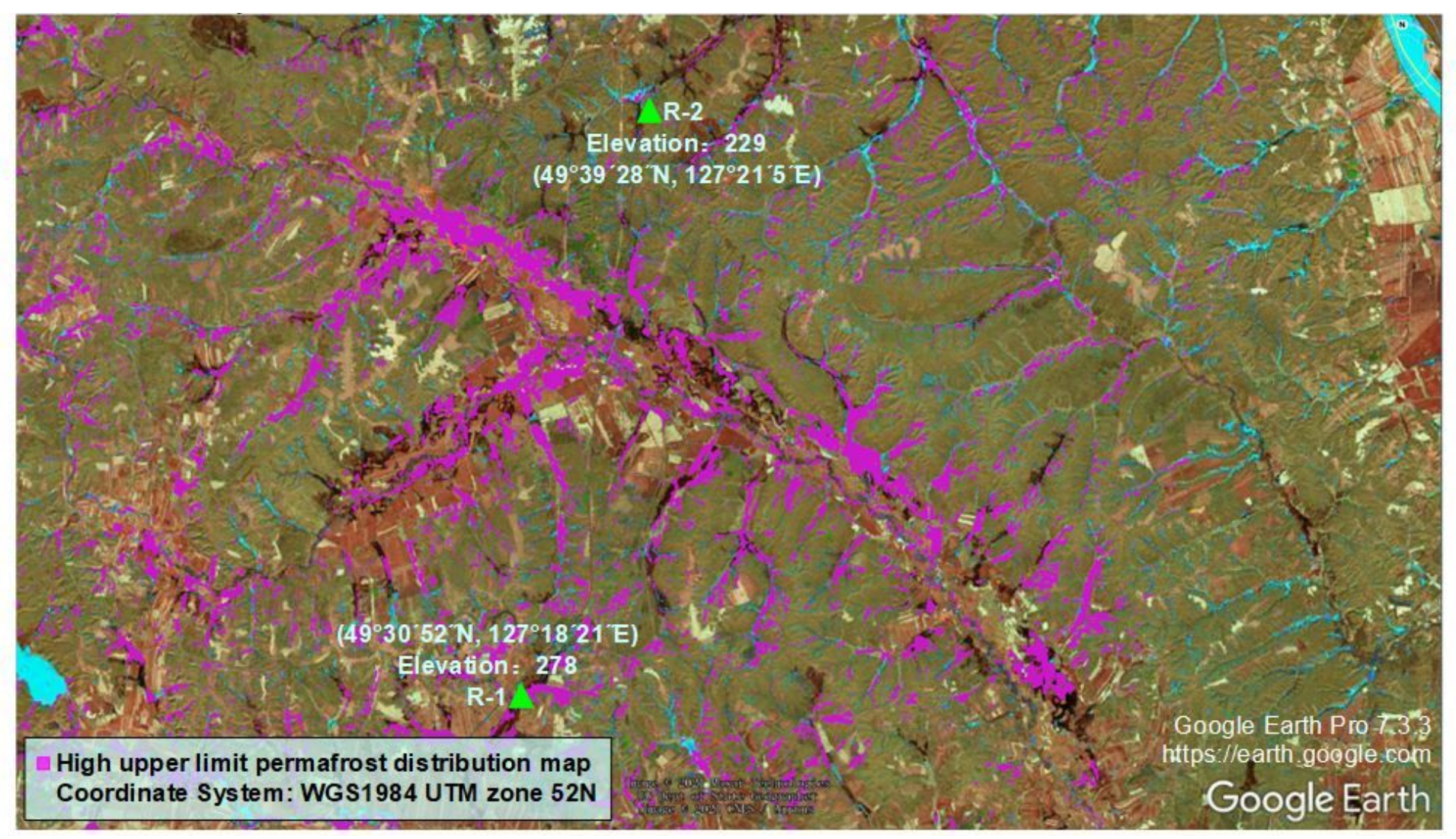

\section{Figure 3}

Location coordinates of R-1 and R-2 in the study area, distribution of frozen soil nearby and burned area (March 24, 2021). The pink area is the distribution area of permafrost, and the data comes from Wang $C$. et al. (2015) 33. Note: The designations employed and the presentation of the material on this map do not imply the expression of any opinion whatsoever on the part of Research Square concerning the legal status of any country, territory, city or area or of its authorities, or concerning the delimitation of its frontiers or boundaries. This map has been provided by the authors. 


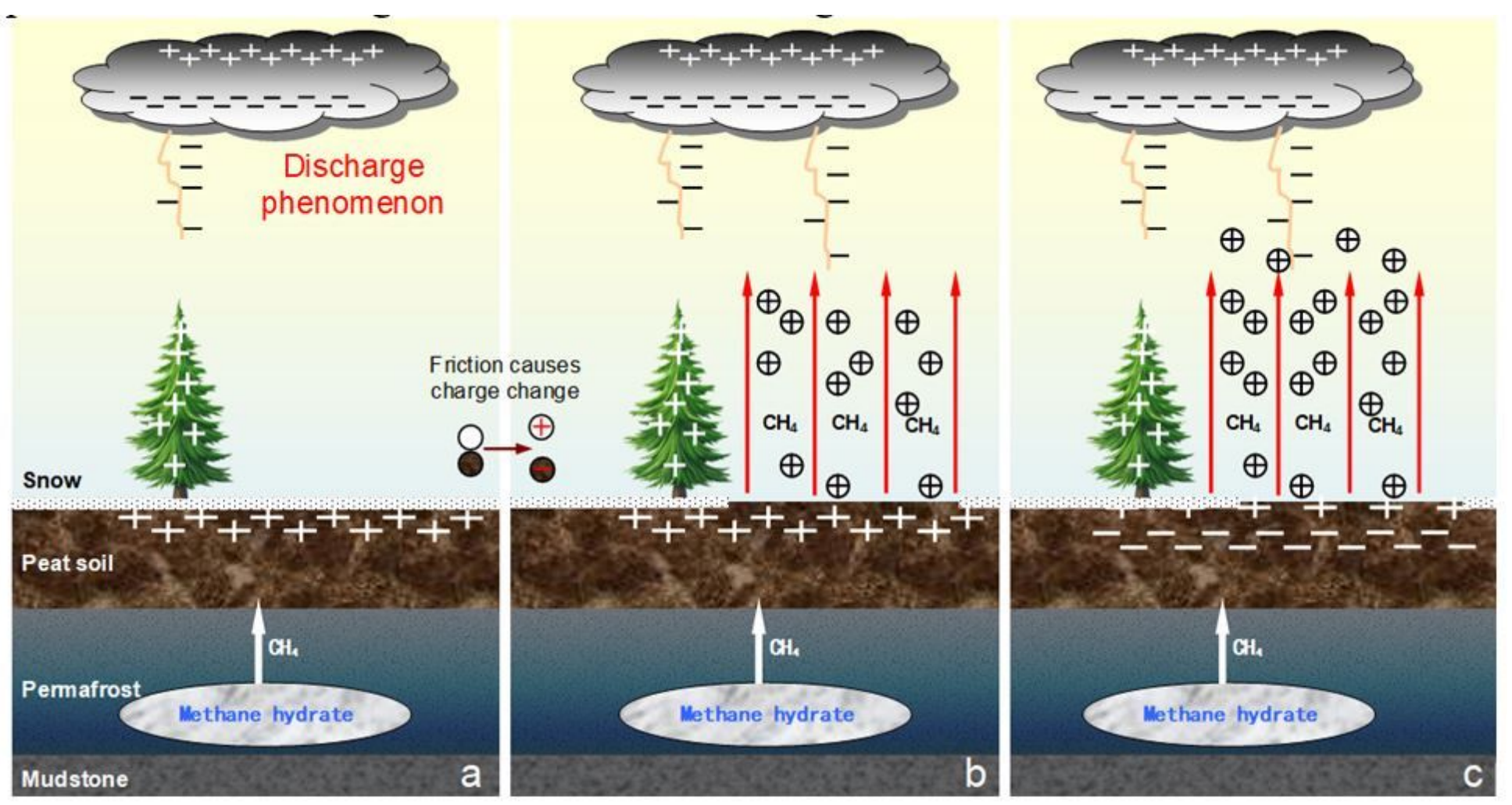

\section{Figure 4}

Conceptual model of electric charge moving with methane gas. a When the frozen layer and snow are not melted, positive charges on the ground gradually accumulate in high places (trees, etc.) to form a positive charge flow column, and contact with stepped leader in the air to cause discharge, b After the frozen layer and snow melt, the positive charges on the ground gradually accumulate in high places (trees, etc.) to form a positive charge flow column. The methane gas discharged outside strengthens the positive charge flow column and contacts the stepped leader, thereby enhancing the air discharge phenomenon. In this process, there are more positive charges on the ground, so the atmospheric electric field near the ground is mainly positive. c After the frozen layer and snow melt, the positive charges on the ground gradually accumulate in high places (trees, etc.) to form a positive charge flow column. The methane gas discharged outside strengthens the positive charge flow column and contacts the stepped leader, thereby enhancing the air discharge phenomenon. With the release of methane, the positive charges gradually enter the atmosphere, the positive charges on the ground gradually decrease, and the atmospheric electric field near the ground is mainly negative. 

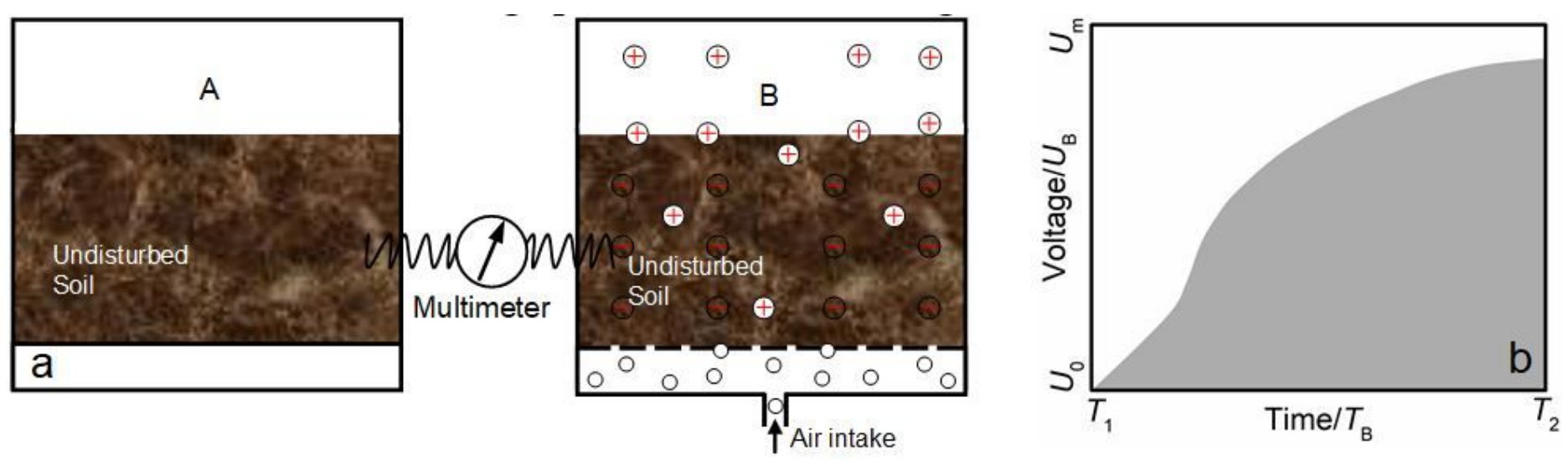

\section{Figure 5}

Schematic diagram of indoor soil ventilation test. a Indoor soil ventilation test, in which test box A is static, and gas input is carried out in the soil of test box $B, b$ Curve of the voltage between the two test box as the gas enters.

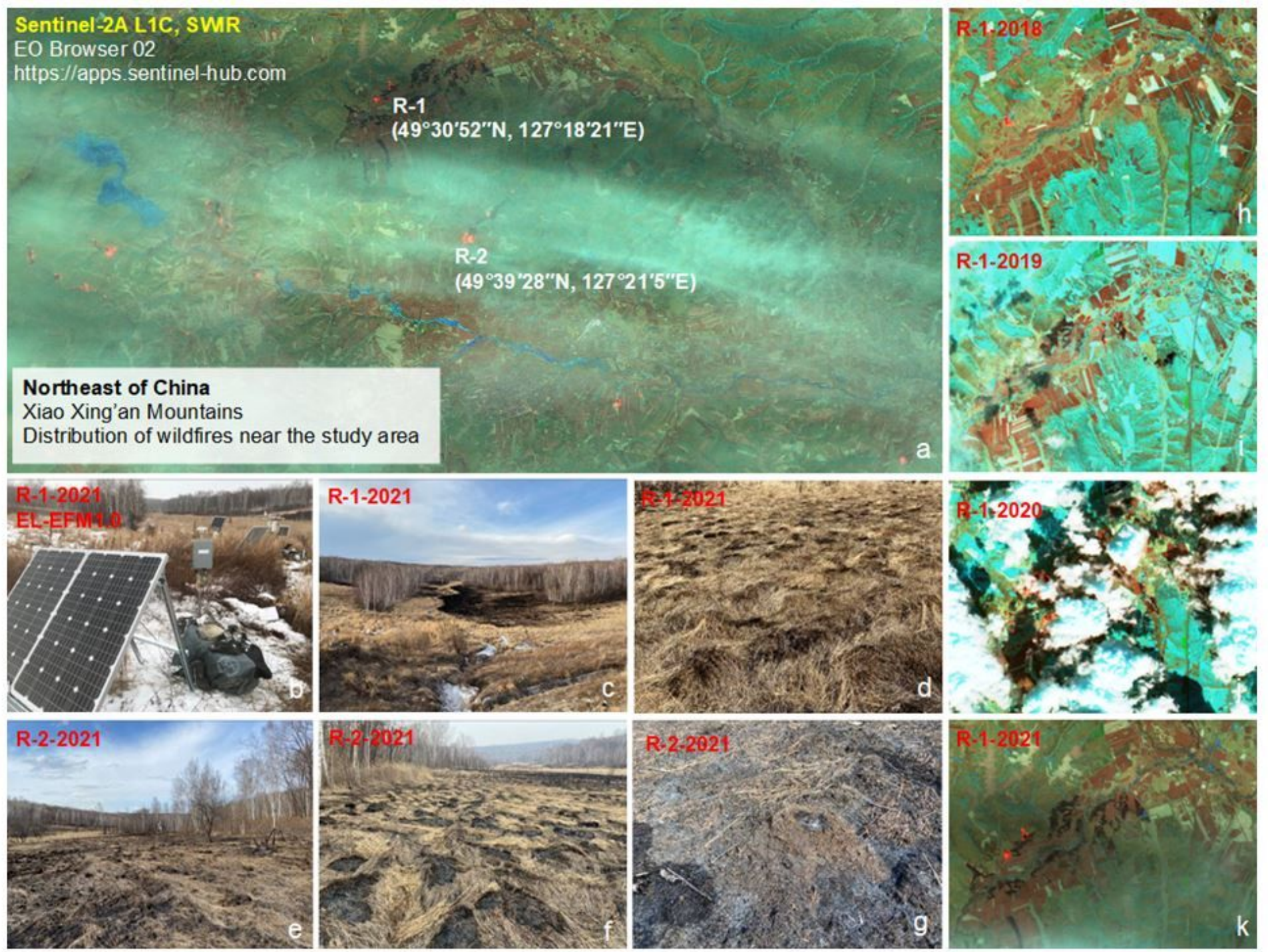

Figure 6 
Wildfire in the study area and on-site photos of the atmospheric electric field instrument. a Wildfire near the study area on March 19, 2021 obtained by sentinel 2 (sentinel-2 L1C), in which the red area was wildfire area, and the black area was burned area, b EL-EFM1.0 atmospheric electric field instrument onsite photos, c Burned area in the study area R-1 on March 19, 2021, d Details of the burned area in the study area R-1 on March 19, 2021, e Burned area in the study area R-2 on March 19, 2021, $f$ Details of the burned area in the study area R-2 on March 19, 2021, g Details of the burned area in the study area R-2 on March 19, 2021, h Wildfire in study R-1 on March 22, 2018 obtained by sentinel 2 (sentinel-2 L1C), i Wildfire in study R-1 on March 22, 2019 obtained by sentinel 2 (sentinel-2 L1C), j Wildfire in study R-1 on March 19, 2020 obtained by sentinel 2 (sentinel-2 L1C), k Wildfire in study R-1 on March 19, 2021 obtained by sentinel 2 (sentinel-2 L1C). 

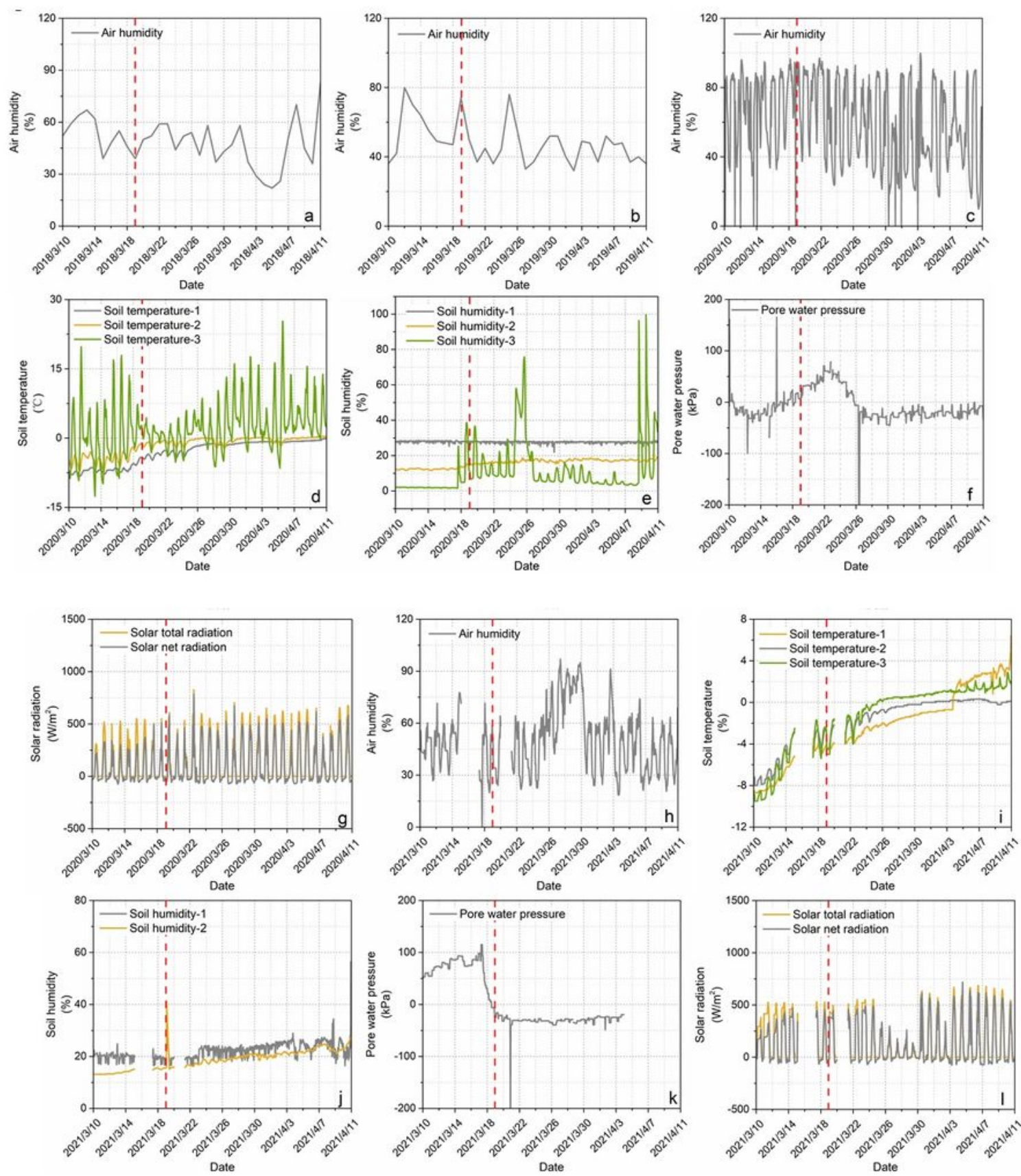

\section{Figure 7}

Change curve of air humidity, soil humidity, soil temperature, pore water pressure and solar radiation in the study area R-1 from March 10 to April 10, 2018-2021. a Air humidity in 2018, b Air humidity in 2019, c Air humidity in 2020, d Soil temperature in 2020, e Soil humidity in 2020, f Pore water pressure in 2020, g Solar radiation in 2020, h Air humidity in 2021, i Soil temperature in 2021, j Soil moisture in 2021 , k pore water pressure in 2021, I Solar radiation in 2021. 


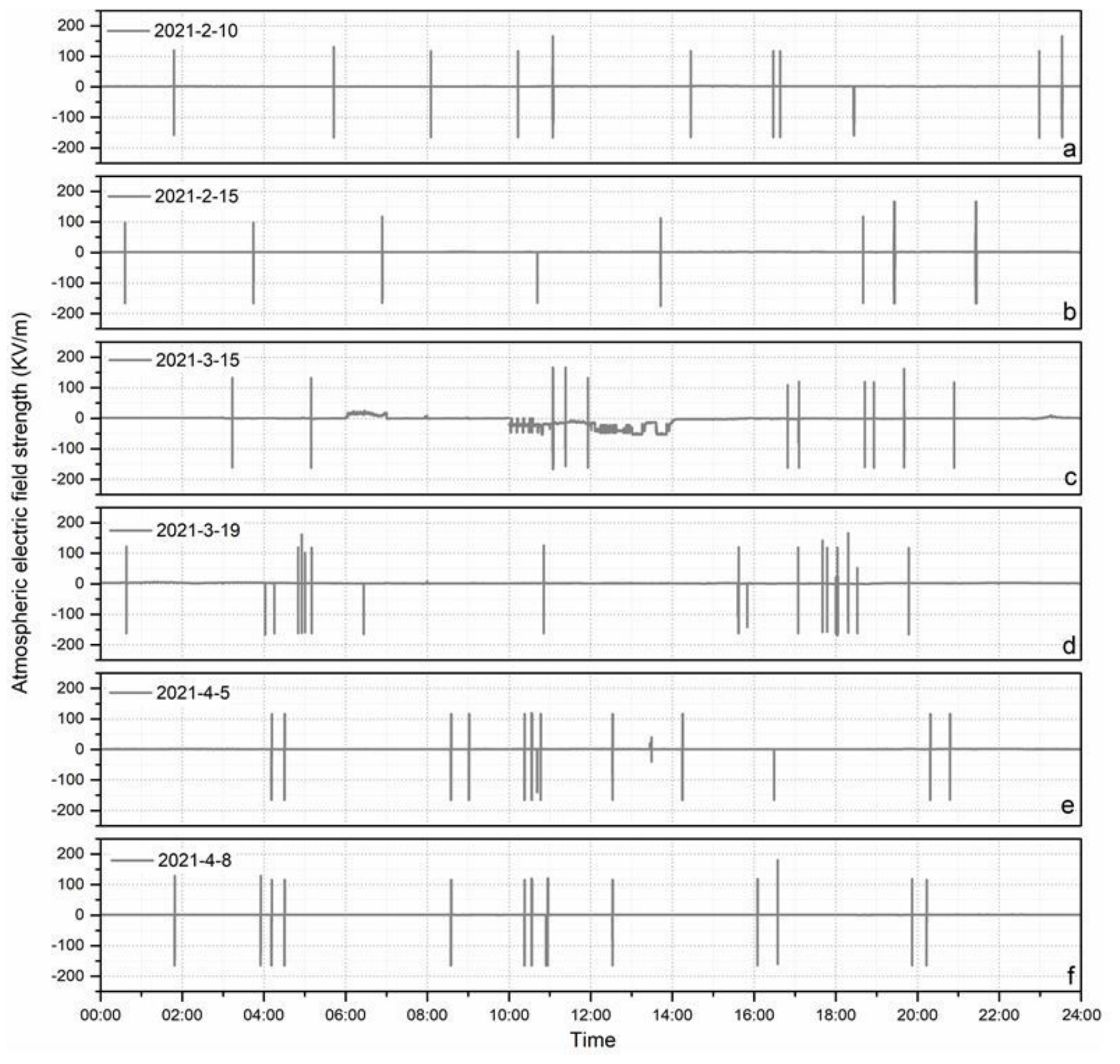

\section{Figure 8}

Change curve of atmospheric electric field. a Change curve of the atmospheric electric field on February 10,2021 , the overall air temperature is negative, and the snow and the frozen layer have not melted, $b$ Change curve of the atmospheric electric field on February 15,2021, the overall atmospheric temperature is negative, and the snow and the frozen layer have not melted., c Change curve of atmospheric electric field on March 15, 2021, the air temperature gradually increases and becomes positive, the snow and the frozen layer gradually melt, among them, there will be snow from 10:00-14:00, $d$ Change curve of atmospheric electric field on March 19, 2021, the air temperature further increased, the snow and frozen layer further melted, and wildfires occurred in the study areas R-1 and R-2, e Air temperature increased on April 5, 2021, and air discharge was more concentrated, $f$ Air temperature increased on April 8, 2021, and air discharge was more concentrated. 

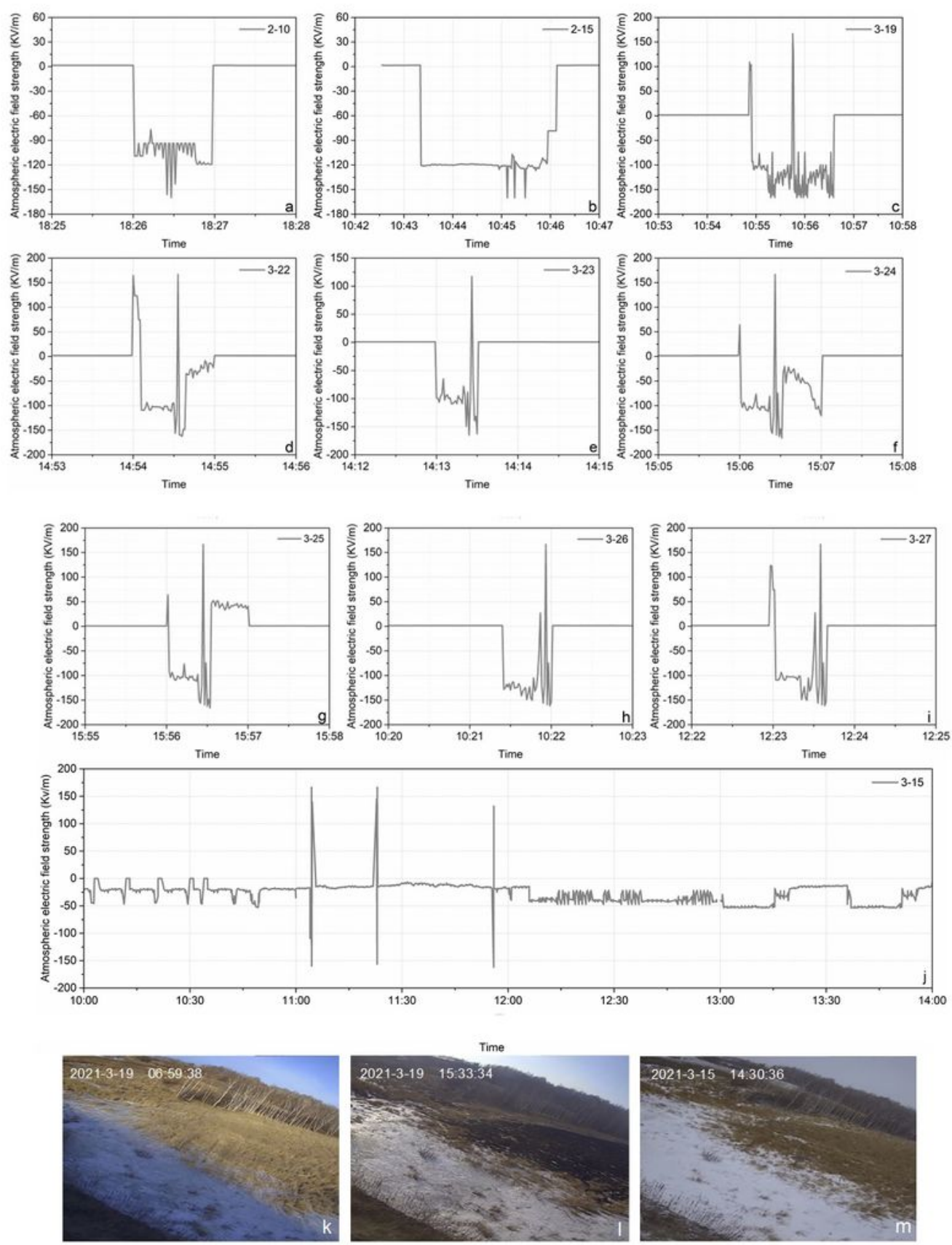

\section{Figure 9}

Local change curve of atmospheric electric field change. a Atmospheric electric field changes on February 10, 2021, b Atmospheric electric field changes on February 15, 2021, c Atmospheric electric field changes on March 19, 2021, d Atmospheric electric field changes on March 22, 2021, e Atmospheric electric field changes on March 23, 2021, f Atmospheric electric field changes on March 24, 2021, g Atmospheric electric field changes on March 25, 2021 h Atmospheric electric field changes on March 26, 2021, i 
Atmospheric electric field changes on March 27, 2021, j Atmospheric electric field changes on March 15, 2021 , the air temperature gradually increased to a positive value that day, and the snow began to melt, there was snowfall from 10:00 to 14:00, and the atmospheric electric field fluctuated significantly, $k$ Onsite photos in study area R-1 at 06:59:38 on March 19, 2021, I On-site photos in study area R-1 at 15:33:34 on March 19, 2021, it can be seen that wildfires occurred between 06:59:38-15:33:34. m On-site photos in study area R-1 at 14:30:36 on March 15, 2021, a large amount of snow appeared on the site after the snowfall from 10:00-14:00.

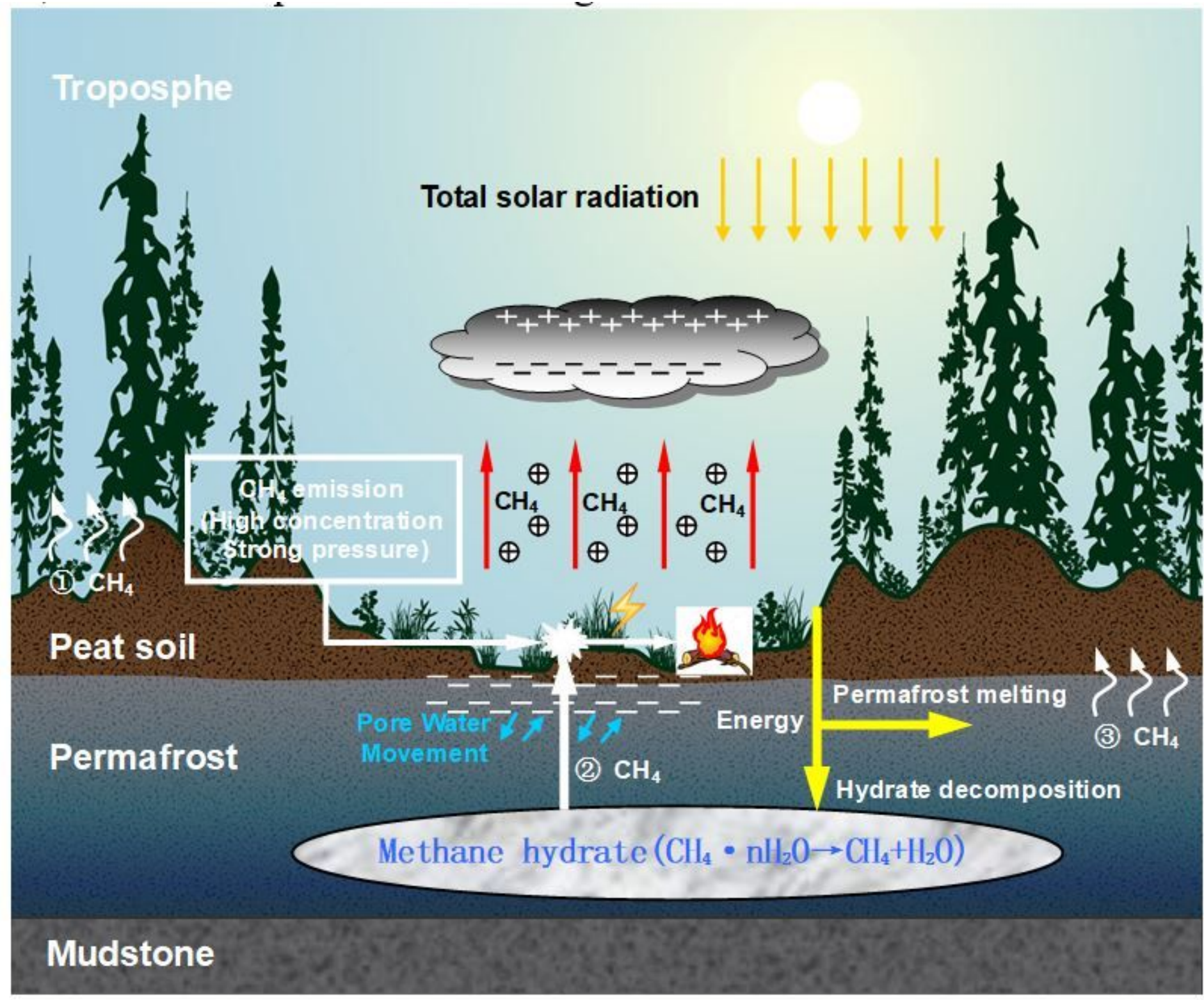

Figure 10

Conceptual model of methane emissions and its impact on wildfires in permafrost63. The top of the soil layer is peat soil with a certain thickness, the bottom is a permafrost layer and contains a certain amount of methane hydrate, and the bottom layer is mudstone. 